Authors Version - Freddi, F., Dimopoulos, C., Karavasilis, T.L. (2020) Experimental evaluation of a rocking damage-free steel column base with friction devices. Journal of Structural Engineering, 146(10): 04020217. ASCE, DOI: 10.1061/ (ASCE)ST.1943-541X.0002779.

\title{
Experimental Evaluation of a Rocking Damage-Free Steel Column Base with Friction Devices
}

\author{
Fabio Freddi ${ }^{1}$, Christoforos A. Dimopoulos ${ }^{2}$, and Theodore L. Karavasilis ${ }^{3}$ \\ ${ }^{1}$ Lecturer, Dept. of Civil, Environmental and Geomatic Engineering, University College London, London WC1E 6BT, U.K. \\ ${ }^{*}$ Corresponding Author. Tel.: +44 (0) 775236 0204. E-mail address: f.freddi@ucl.ac.uk \\ ${ }^{2}$ Lecturer, School of Science, Engineering and Design, Teesside University, Middlesbrough, TS1 3BX, U.K. \\ E-mail address: c.dimopoulos@tees.ac.uk \\ ${ }^{3}$ Associate Professor of Steel Structures, Department of Civil Engineering, University of Patras, GR-26500 Patras, Greece. \\ E-mail address: karavasilis@upatras.gr
}

\section{Abstract}

The paper presents the experimental evaluation of an earthquake-resilient rocking damage-free steel column base, previously proposed and numerically investigated by the authors. The column base uses post-tensioned high-strength steel bars to control its rocking behavior and friction devices to dissipate seismic energy. It is equipped with a circular steel plate with rounded edges, which is used as a rocking base. The rounded edges prevent stress concentration and damage of the contact surfaces, while the circular shape allows rocking towards all plan directions. Contrary to conventional steel column bases, the proposed column base exhibits monotonic and cyclic moment-rotation behaviors that are easily described by analytical equations. The latter allow the definition of a step-by-step design procedure, which ensures damage-free behavior, selfcentering capability and energy dissipation capacity for a target design base rotation. The experimental tests are conducted under monotonic and cyclic loads demonstrating the damage-free behavior even under large rotations. Then, the experimental results are used to validate the design procedure and to calibrate refined 3D nonlinear finite element models in ABAQUS that will allow further investigations.

KEY WORDS: Damage-free column base; Experimental test; Steel frames; Rocking; Seismic design; Structural Resilience.

\section{INTRODUCTION}

Conventional seismic-resistant structures, such as steel moment-resisting frames (MRFs) or concentrically braced frames, are designed to experience significant inelastic deformations under strong earthquakes (e.g., EN1998-1-1 2005; FEMA 2000). Inelastic deformations can result in damage to the structural members and residual drifts, leading to high repair costs and disruption of the building occupation. The aforementioned socio-economic risks highlight the need for widespread implementation of minimal-damage structures, which can reduce both repair costs and downtime. Examples of such structures include self-centering moment-resisting frames (SC-MRF), systems employing structural 
fuses, passive energy dissipation devices, self-centering braces, among others (e.g., Garlock et al 2007; Kim and

33 Christopoulos 2008; Vasdravellis et al 2013; Dimopoulos et al 2016; Tzimas et al 2016; Dimopoulos et al 2019;

34 Blomgren et al 2019; Symans et al 2008; Akcelyan et al 2016; Freddi et al 2013; Gioiella et al 2018). These

35 earthquake-resilient steel frame typologies have been extensively studied during the last decade, however, further

36 studies are needed to improve the behavior of their column bases.

37 Based on the capacity design philosophy of Eurocode 8 (2005) (EN 1998-1-1 2005), conventional steel column

38 bases can be designed as full- or partial-strength joints. In the first approach, plastic hinges are developed in the bottom

39 end of the first story columns, while in the second, the column bases are designed to dissipate energy through inelastic

40 deformations in their main components (i.e., base plates, anchor rods) (EN 1998-1-1 2005; EN 1993-1-8 2005). The

41 design of full-strength joints leads to very strong column bases due to the over-strength factors that account for

42 material variability (Latour and Rizzano 2013) and to conservative foundation designs because the full moment

43 resistance of the column profile is transferred to the foundation. On the other hand, the design of partial-strength joints

44 allows better control of the dimensions of the column bases but requires knowledge of its complex hysteretic behavior

45 under cyclic loading, which is difficult to predict and is affected by strength and stiffness degradation (Latour and

46 Rizzano 2013; Rodas et al 2016). Most importantly, for both approaches, field observations after strong earthquakes

47 have confirmed the susceptibility of column bases to difficult-to-repair damage and residual deformations related to concrete crushing, weld fracture, anchor rod fracture, and base plate yielding (Grauvilardell et al 2006). In design

49 practice, column bases are assumed to behave as a fully fixed or pinned connection and such assumption may either

50 underestimate or overestimate the story drifts and internal member forces, thus leading to uneconomical or 51 unconservative designs (Zareian and Kanvinde 2013; Kanvinde et al 2012).

52 A number of research efforts have proposed alternative solutions with the goal of overcoming the shortcomings of 53 conventional column bases (e.g., Kelly and Tsztoo 1977; Ikenaga et al 2006; Mackinven et al 2007; Chou and Chen

54 2011; Chi and Liu 2012; Yamanishi et al 2012; Takamatsu and Tamai 2005; Grigorian et al 1993; MacRae et al 2009;

55 Borzouie et al 2015; Latour et al 2019; Kamperidis et al 2018; Wang et al 2019; Freddi et al 2017). Among the first 56 attempts to develop minimal-damage column bases, Kelly and Tsztoo (1977), proposed and experimentally 57 investigated a partial isolation system associated with an energy-absorbing device that could be easily replaced after 58 an earthquake. The results of this study demonstrated the advantages of damage-free structural systems and promoted 59 many successive studies in this direction.

60 Some of these research works (e.g., Ikenaga et al 2006; Mackinven et al 2007; Chou and Chen 2011; Chi and Liu 
2012; Yamanishi et al 2012; Takamatsu and Tamai 2005), have focused on the use of rocking column bases where

62 post-tensioned (PT) bars, or yielding bolts, were used to control rocking behavior and to provide self-centering

63 capability, while dedicated devices were used to dissipate seismic energy. Several different configurations were

64 investigated considering different column sections, different lengths and different positions of the PT bars. Two

65 examples of these column bases, respectively by Chi and Liu (2012) and by Yamanishi et al (2012) are illustrated in

66 Fig. 1(a) and (b). While in some cases the results showed the advantages of the system in terms of improved self-

67 centering behavior of the column base, several drawbacks were also highlighted including undesirable column axial

68 shortening, loss of post-tensioning force and inelastic deformations. Alternatively, based on the concept of beam-to-

69 column connections with friction devices (FDs), originally pioneered by Grigorian and Popov (1993), other authors

70 further extended this idea to column bases. MacRae et al (2009) and Borzouie et al (2015) developed two different

71 configurations of column base where the moment resistance and the energy dissipation were provided by friction

72 resistance activated by the relative movement of the column flanges with respect to foundation flange plates with

73 slotted holes. These configurations, respectively illustrated in Fig. 1(c) and (d), allowed to achieve superior behavior

74 under loading in the column strong-axis direction, while damage and stiffness degradation was observed under loading

75 of the column in the weak-axis direction.

76 Recently, Latour et al (2019) developed a self-centering base plate connection where FDs were coupled with pre-

77 loaded threaded bars and disk springs as illustrated in Fig. 1(e). The experimental results demonstrated that the system

78 was able to provide energy dissipation and self-centering capabilities along with damage-free behavior. In addition,

79 Kamperidis et al (2018) and Wang et al (2019)! studied two types of low-damage self-centering steel column base

80 connections illustrated respectively in Fig. 1(f) and (g). In both cases, the column base was composed by a concrete-

81 filled square steel section and used external PT strands to control rocking behavior. Two different types of yielding

82 devices, respectively hourglass shape steel yielding devices and sandwiched energy dissipaters, were used to dissipate

83 the seismic energy. Both the numerical simulations and the experimental results demonstrated self-centering behavior

84 and stable energy dissipation of both column base connections demonstrating low residual drifts. However, all the

85 configurations investigated and described so far, do not prevent high stress concentration and damage at the onset of

86 rocking. In addition, they do not provide solutions to control the response of the column base in different plan

87 directions except from the principal direction of the column cross-section. 

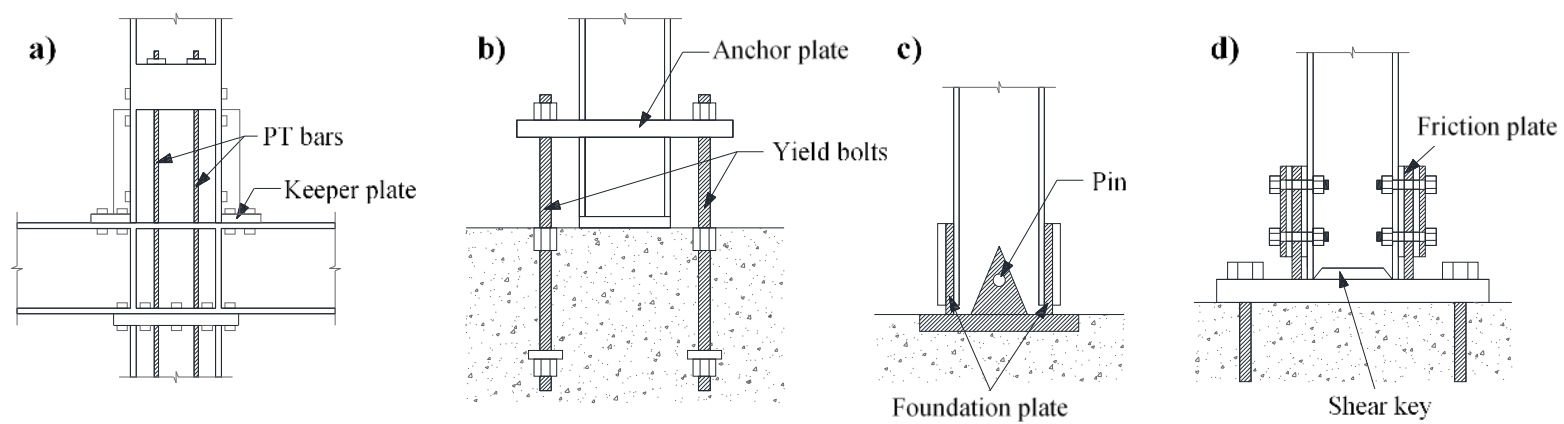

e)

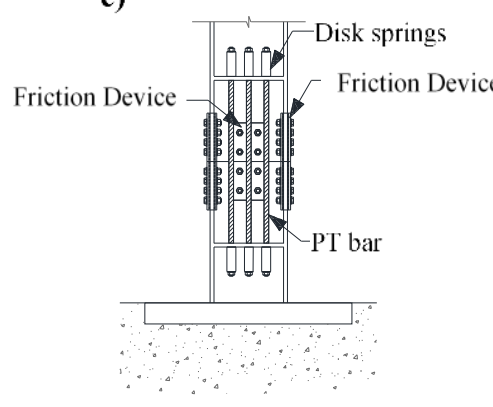

f)

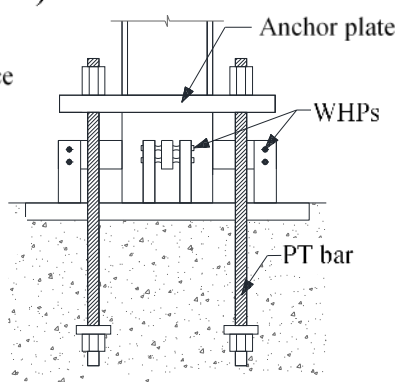

g)

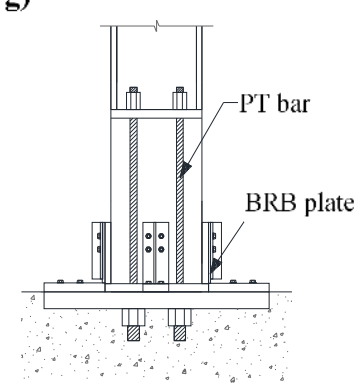

Fig. 1. Novel CBs proposed by: (a) Chi and Liu (2012); (b) Yamanishi et al (2012); (c) MacRae et al (2009); (d) Borzouie et al (2015); (e) Latour et al (2019); (f) Kamperidis et al (2018); (g) Wang et al (2019).

In 2017, Freddi et al (2017) proposed and numerically investigated a rocking damage-free steel column base, that can be employed to reduce residual deformations and damage in 'innovative' MRFs. The proposed column base, similarly to previous studies, used PT high-strength steel bars to control the rocking behavior while FDs were used to dissipate the seismic energy. Amongst others, the main advances with respect to other studies, relates to the circular steel plate with rounded edges which is used as rocking base. The rounded edges prevent stress concentration and damage of the contact surfaces while rocking, while the circular shape allows rocking in all plan directions. Freddi $e t$ al (2017) provided simple analytical equations to describe both the monotonic and cyclic moment-rotation behavior considering also the possible limit states. These allowed the definition of a design procedure based on non-dimensional parameters and a simple graphical tool. Both the analytical moment-rotation equations and the design procedure were validated with the aid of 3D nonlinear finite element (FE) simulations in ABAQUS (2013) that allowed also to evaluate the local behavior of the components. On the other side, a simplified 2D model of the rocking column base was also developed in OpenSees (2006) (McKenna et al 2006) to assess the influence of the proposed column base on the global behavior of a structural system. The OpenSees model was used to conduct nonlinear dynamic analyses on a five-story, five-bay by three-bay steel SC-MRFs with the conventional and proposed rocking column base. The results 
107 showed that the proposed rocking column base can fully protect the first story columns from yielding and eliminates

108 the first story residual drift without detrimental effects on peak inter-story drifts.

109 The present paper experimentally evaluates a 3/5 scaled specimen of the rocking damage-free steel column base

110 proposed in Freddi et al (2017) under monotonic and cyclic quasi-static loads. The experimental campaign included

111 tests for the characterization of the FDs, required for the definition of important parameters, such as the friction

112 coefficient of the sliding materials and coupon tests for the characterization of the materials. The experimental results

113 demonstrated the damage-free behavior of the column base up to the target design rotation and the ability to limit

114 damage only to few easily replaceable components even under large rotations. The experimental results were also

115 compared and used to calibrate FE models in ABAQUS that will allow further numerical investigations.

\section{2. ROCKING DAMAGE-FREE STEEL COLUMN BASE}

\section{2.1 Structural details}

118 Fig. 2 shows the column base proposed and numerically evaluated by Freddi et al (2017). A thick steel plate with 119 rounded edges is welded to the bottom of a circular hollow steel section. The rounded edges help the column base to 120 avoid stress concentrations and damage while rocking. Four PT high strength steel bars (or alternatively strands) are 121 symmetrically placed around the center of the column base to increase the axial force in the column and further control 122 the rocking behavior. The PT bars are anchored to the bottom of the foundation (by running them through steel ducts) 123 and to a thick plate welded on the top of the hollow steel section (see the anchor plate in Fig. 2(a)). FDs are placed on 124 the four sides of the column base to provide energy dissipation during rocking. As shown in Fig. 3(a), the FDs consist 125 of two external steel plates bolted to the base plate, an internal steel plate welded to the circular hollow section, and 126 two plates of brass material glued to the external plates at the interface between the external and internal plates.

127 Rocking of the column base results in sliding of the internal plate with respect to the brass and external plates, and 128 thus, dissipates energy through friction. The internal plate is drilled with inclined slotted holes to enable sliding, while 129 the external plates and the brass plates are drilled with aligned rounded holes to accommodate pre-tensioned bolts that 130 are used to tune the friction force in the FDs. The dimensions of the inclined slotted holes are chosen to accommodate 131 the superposition of all possible bolt travel paths during rocking, as shown in Fig. 3(a) (Wolski et al 2009). Shear 132 resistance is provided by friction between the base plate and the circular steel section, while as shown in Fig. 3(b), a 133 shear key is included to prevent sliding in case the shear force overcomes the friction resistance. The shear key is 134 designed, such that in the absence of slippage, there is no contact between its coupling parts during rocking. 
136 Fig. 4(a) shows the dimensions of the column base that control the moment-rotation behavior in the rocking direction, 137 i.e., $b$ is the dimension of the contact surface; $b_{\mathrm{PT}}$ is the distance among the PT bars; $b_{\mathrm{FD}}$ is the distance among the 138 centers of the FDs and $h_{\mathrm{FD}}$ is the distance of the centers of the FDs from the base plate. Fig. 4(b) shows the column 139 base at the onset of rocking with respect to its right edge under the effect of the internal axial force $(N)$, shear force $140(V)$, and bending moment $(M)$. In Fig. 4(b), $F_{\mathrm{PT}, \mathrm{u}}$ and $F_{\mathrm{PT}, \mathrm{d}}$ are the forces in the PT bars, while $F_{\mathrm{FD}, \mathrm{u}}, F_{\mathrm{FD}, \mathrm{d}}$ and $F_{\mathrm{FD}, \mathrm{c}}$

141 are the forces in the FDs. The subscripts $u$ and $d$ denote whether the point of application of these forces will move 142 upwards or downwards during rocking. The subscript $c$ denotes the force in each of the two central FDs. The lever 143 arms of the forces with respect to the center of rotation $z_{\mathrm{PT}, \mathrm{u}}, z_{\mathrm{PT}, \mathrm{d}}, z_{\mathrm{FD}, \mathrm{u}}, z_{\mathrm{FD}, \mathrm{c}}, z_{\mathrm{FD}, \mathrm{d}}$ are easily derived from the main 144 dimensional parameters as discussed in Freddi et al (2017).
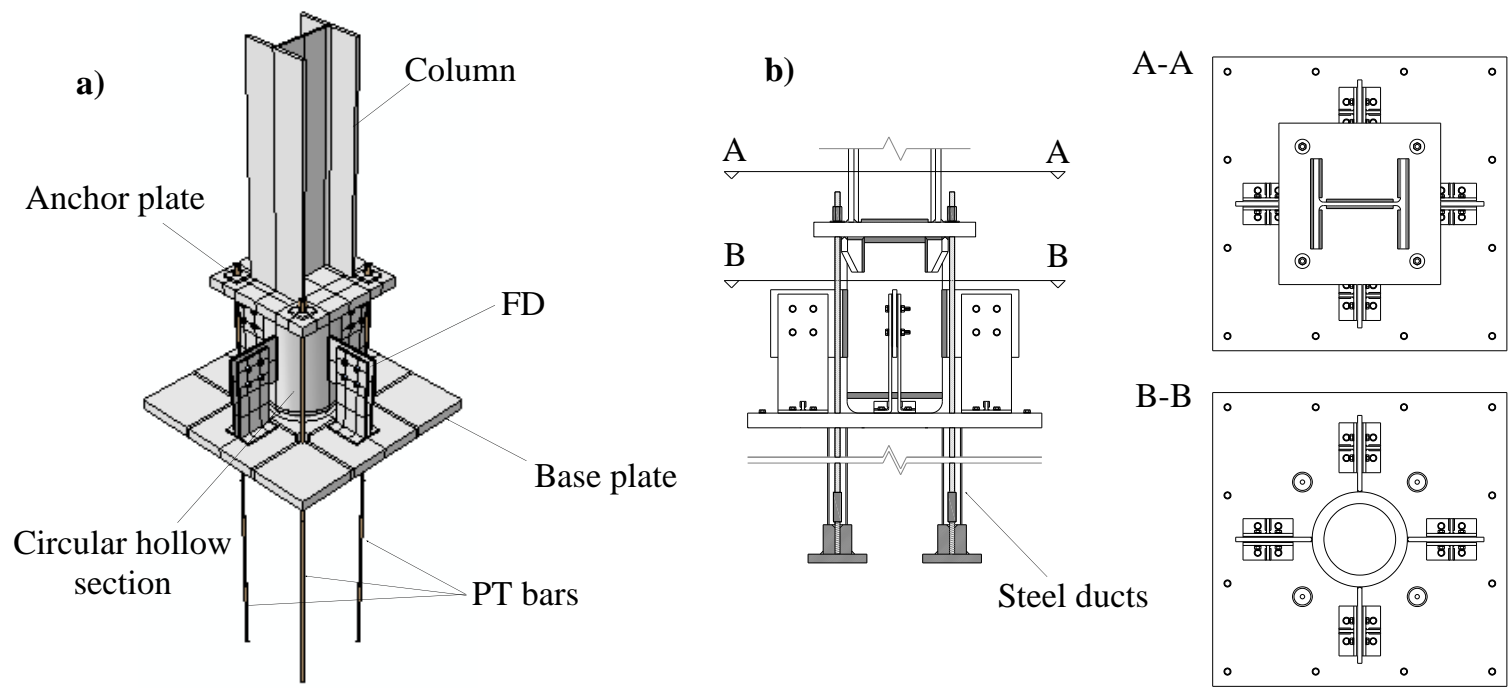

145 Fig. 2. Column base (a) 3D view and (b) lateral view and sections
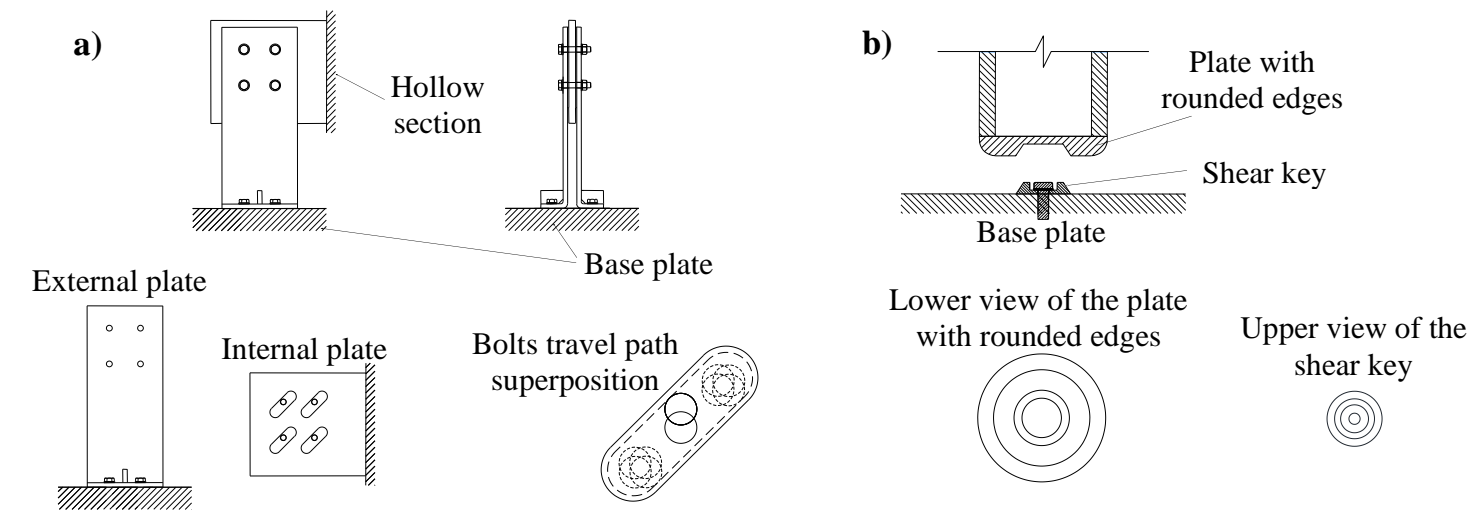

146 Fig. 3. (a) Details of the friction device (FD) and (b) steel plate with rounded edges and shear key 
The moment contribution of the axial force, $N$, is given by

$$
M_{\mathrm{N}}=N \cdot \frac{b}{2}
$$

The forces in each PT bar are function of the rotation, $\theta$, of the column base and are given by

$$
\begin{array}{ll}
F_{\mathrm{PT}, \mathrm{u}}=T_{\mathrm{PT}}+K_{\mathrm{PT}} \cdot z_{\mathrm{PT}, \mathrm{u}} \cdot \theta & \text { for } \quad \theta \leq \theta_{\mathrm{PT}, \mathrm{u}, \mathrm{y}} \\
F_{\mathrm{PT}, \mathrm{d}}=T_{\mathrm{PT}}-K_{\mathrm{PT}} \cdot z_{\mathrm{PT}, \mathrm{d}} \cdot \theta & \text { for } \quad \theta \leq \theta_{\mathrm{PT}, \mathrm{d}, \mathrm{f}}
\end{array}
$$

153 where $T_{\mathrm{PT}}$ is the initial post-tensioning force of each PT bar; $K_{\mathrm{PT}}=E_{\mathrm{PT}} A_{\mathrm{PT}} / L_{\mathrm{PT}}$ is the stiffness of each PT bar; $E_{\mathrm{PT}}, A_{\mathrm{PT}}$ 154 and $L_{\mathrm{PT}}$ are respectively the Young's modulus, the cross-sectional area, and the length of each PT bar; $\theta_{\mathrm{PT}, \mathrm{u}, \mathrm{y}}$ is the 155 rotation at which the PT bars (in position $u$ ) yield; and $\theta_{\mathrm{PT}, \mathrm{d}, \mathrm{f}}$ is the rotation at which the force of the PT bars (in 156 position $d$ ) becomes zero, i.e., when loss of post-tensioning occurs. The PT bars should be designed to avoid either 157 yielding or loss of post-tensioning for a target rotation $\theta_{\mathrm{T}}$. The moment contribution of the PT bars is given by

$$
M_{\mathrm{PT}}(\theta)=2\left[T_{\mathrm{PT}}\left(z_{\mathrm{PT}, \mathrm{u}}-z_{\mathrm{PT}, \mathrm{d}}\right)+K_{\mathrm{PT}}\left(z_{\mathrm{PT}, \mathrm{u}}^{2}+z_{\mathrm{PT}, \mathrm{d}}^{2}\right) \theta\right] \quad \text { for } \theta \leq \theta_{\mathrm{T}}
$$

159 The friction force, $F_{\mathrm{FD}, \text {, }}$, for each friction surface is given by

$$
F_{\mathrm{FD}, \mathrm{i}}=\mu_{\mathrm{FD}} \cdot n_{\mathrm{b}} \cdot N_{\mathrm{b}} \quad \text { with } \mathrm{i}=u, c, d
$$

161 where $\mu_{\mathrm{FD}}$ is the friction coefficient of the surfaces in contact; $n_{\mathrm{b}}$ is the number of bolts and $N_{\mathrm{b}}$ is the bolt pre-loading 162 force. The moment contribution of the FDs is given by

$$
M_{\mathrm{FD}}=n_{\mathrm{FD}} \cdot F_{\mathrm{FD}}\left(z_{\mathrm{FD}, \mathrm{u}}+2 \cdot z_{\mathrm{FD}, \mathrm{c}}+z_{\mathrm{FD}, \mathrm{d}}\right)
$$

164 Fig. 5(a) shows the moment contributions of the axial force, $M_{\mathrm{N}}$; of the PT bars, $M_{\mathrm{PT}}$; and of the FDs, $M_{\mathrm{FD}}$. The decompression moment, $M_{\mathrm{E}}$, and the moment at the onset of rocking, $M_{\mathrm{D}}$, are given by

$$
M_{\mathrm{E}}=M_{\mathrm{N}}+M_{\mathrm{PT}, 0} \quad M_{\mathrm{D}}=M_{\mathrm{E}}+M_{\mathrm{FD}}
$$

167 where $M_{\mathrm{PT}, 0}$ is the moment provided by the PT bars at zero rotation, i.e., $\theta=0.0$ in Eq. (3). 
a)

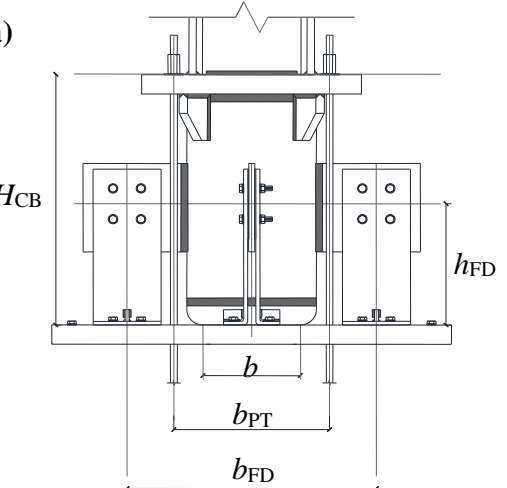

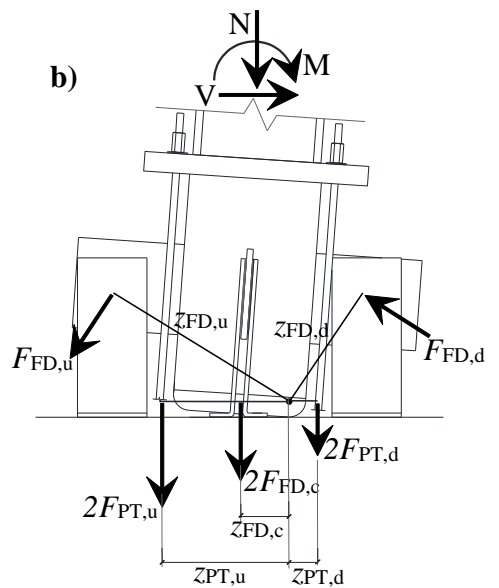

168

169

170

171

172

173

174 The rotational stiffness contribution of the PT bars and the moments corresponding to points 1 to 4 of the cyclic

a)

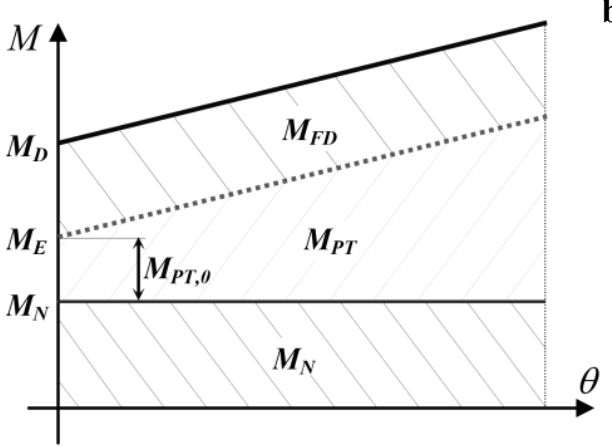

b)

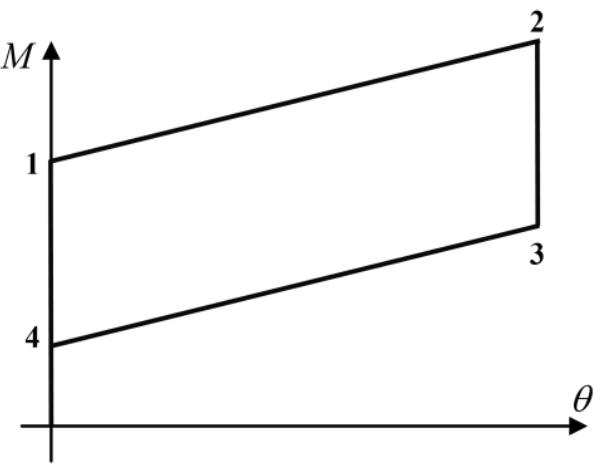

Fig. 5. Moment-rotation behavior of the column base. (a) Moment contribution of the axial force, $M_{\mathrm{N}}$; of the posttensioned (PT) bars, $M_{\mathrm{PT}}$; and of the friction devices (FDs), $M_{\mathrm{FD}}$ and (b) hysteretic behavior moment-rotation behavior of the column base in Fig. 5(b) are given by

$$
S_{\mathrm{PT}}=2 K_{\mathrm{PT}}\left(z_{\mathrm{PT}, \mathrm{u}}^{2}+z_{\mathrm{PT}, \mathrm{d}}^{2}\right)
$$

$$
M_{1}=M_{\mathrm{D}}=M_{\mathrm{N}}+M_{\mathrm{PT}, 0}+M_{\mathrm{FD}}
$$

$$
M_{2}=M_{\mathrm{D}}+S_{\mathrm{PT}} \theta_{2}
$$

$$
M_{3}=M_{\mathrm{D}}+S_{\mathrm{PT}} \theta_{2}-2 M_{\mathrm{FD}}
$$

$$
M_{4}=M_{\mathrm{D}}-2 M_{\mathrm{FD}}
$$

181 To ensure that the column base provides full self-centering capability, the following relation should be satisfied 


\section{3. SPECIMEN DESIGN}

184 A column extracted from a building frame was used as case study for the experimental tests. The minimum and 185 maximum axial forces, $N_{\mathrm{Ed}}$, from the seismic load combination were equal to $510.3 \mathrm{kN}$ and $565.3 \mathrm{kN}$, respectively.

186 The axial force from the gravity load of the seismic load combination, $N_{\mathrm{Ed}, \mathrm{G}}$, was equal to $537.8 \mathrm{kN}$ and was employed

187 for the design, while the minimum and maximum forces were successively used to assess its adequacy. The cross188 section of the column is a HEB 300.

189 The experimental test was conducted on a $3 / 5$ scaled model (i.e., scaling factor $\lambda=0.6$ ) of the prototype column 190 base. The specimen of the column base was designed based on the dimensions of the scaled column. The scaling factor $191 \lambda=0.6$ was chosen based on the capabilities of the lab and the model scaling was made assuming material scaling 192 identity. Length units were scaled by $\lambda$ while areas and forces were scaled by $\lambda^{2}$. Table 1 contains a comprehensive 193 list of the similitude scaling factors between the prototype and the test frames.

Table 1. Similitude scaling factors

\begin{tabular}{llll}
\hline Scaling quantity & Units & $\begin{array}{l}\text { Dimensional scale } \\
\text { requirement }\end{array}$ & $\begin{array}{l}\text { Required scale } \\
\text { factor }\end{array}$ \\
\hline Stress & $\mathrm{S}$ & 1 & 1 \\
Length or Displacement & $\mathrm{L}$ & $\lambda$ & 0.6 \\
Area & $\mathrm{L}^{2}$ & $\lambda^{2}$ & 0.36 \\
Section Moduli & $\mathrm{L}^{3}$ & $\lambda^{3}$ & 0.216 \\
Moment of Inertia & $\mathrm{L}^{4}$ & $\lambda^{4}$ & 0.1296 \\
Force & $\mathrm{F}=\mathrm{S} \times \mathrm{L}^{2}$ & $\lambda^{2}$ & 0.36 \\
Moment & $\mathrm{F} \times \mathrm{L}=\mathrm{S} \times \mathrm{L}^{3}$ & $\lambda^{3}$ & 0.216 \\
\hline
\end{tabular}

The column used in the experimental test was a UC $203 \times 203 \times 46$, which has similar dimensions with the prototype 197 column base HEB 300 scaled by $\lambda$. The maximum $N_{\mathrm{Ed}}$ and $N_{\mathrm{Ed}, \mathrm{G}}$ scaled by $\lambda^{2}$ are equal to $203.5 \mathrm{kN}$ and $193.6 \mathrm{kN}$, 198 respectively. The bending moment resistance $M_{\mathrm{N}, \mathrm{Rd}}$ evaluated according to the Eurocode 3 (2005) (EN 1993-1-1 2005) 199 is not influenced by the axial force up to a value $N_{\mathrm{Ed}}$ equal to $247 \mathrm{kN}$, and hence, for the considered case, the bending 200 moment resistances in the two directions are $M_{\mathrm{N}, \mathrm{Rd}, \mathrm{y}}=176.58 \mathrm{kNm}$ and $M_{\mathrm{N}, \mathrm{Rd}, \mathrm{z}}=81.97 \mathrm{kNm}$, respectively. The target 201 rotation was assumed equal to $\theta_{\mathrm{T}}=0.03 \mathrm{rad}$.

202 Based on the geometry of the column cross-section, the fundamental dimensions of the column base (i.e., $b, b$ PT, $203 b_{\mathrm{FD}}$, and $\left.h_{\mathrm{FD}}\right)$ were selected. A circular hollow section with a $193.7 \mathrm{~mm}$ diameter and $30 \mathrm{~mm}$ thickness was adopted. 204 A circular steel plate with the same diameter was welded at the bottom of the hollow section. Standard mechanical 
processing provided this plate with rounded circular edges having a radius of $30 \mathrm{~mm}$ as well as with appropriate space

206 to accommodate the shear key. The contact surface had a dimension $b$ equal to $143 \mathrm{~mm}$. Due to low availability of PT

207 bars with small dimensions, 7 wire strands complying with the requirements of the BS 5896: 2012 (2012), were used

208 in the experiment. The anchor plate of the post-tensioned strands in the top of the hollow steel section was rectangular

209 and had width, length, and thickness equal to $330 \mathrm{~mm}, 415 \mathrm{~mm}$ and $50 \mathrm{~mm}$, respectively, while the distance between

210 the strands $b_{\mathrm{PT}}$ was equal to $255 \mathrm{~mm}$. The material properties assumed for the design, which are reported in Table 2

$211\left(f_{\mathrm{y}}\right.$ : yield stress; $f_{\mathrm{u}}$ : ultimate stress; $E$ : Young's modulus; $\beta$ : strain hardening ratio and $v$ : Poisson's coefficient), were

212 selected on the basis of experimental results (Coelho et al 2004; Haremza et al 2013) and on test certificates provided

213 by the suppliers.

214 Table 2. Material properties assumed for the design

\begin{tabular}{lclllll}
\hline \multirow{2}{*}{ Elements } & & $f_{\mathrm{y}}$ & $f_{\mathrm{u}}$ & $E$ & $\beta$ & $v$ \\
& & {$[\mathrm{MPa}]$} & {$[\mathrm{MPa}]$} & {$[\mathrm{GPa}]$} & & \\
\hline Column and plates & S 355 JR & 355 & 510 & 210 & 0.00338 & 0.30 \\
Post-tensioned strands & BS 5896:2012 & 1885 & 1995 & 195 & 0.01193 & 0.30 \\
Bolts & Class 10.9 & 900 & 1000 & 210 & 0.00855 & 0.30 \\
Brass & C46400 half hard & 200 & 450 & 100 & 0.00839 & 0.35 \\
\hline
\end{tabular}

216 The design was performed according to the methodology proposed by Freddi et al (2017), which is based on the 217 following Eqs.

$$
\kappa=\frac{1}{2 A_{\mathrm{PT}} f_{\mathrm{y}, \mathrm{PT}}\left(z_{\mathrm{PT}, \mathrm{u}}-z_{\mathrm{PT}, \mathrm{d}}\right)}\left[\frac{M_{\mathrm{T}}-2 \frac{E_{\mathrm{PT}} A_{\mathrm{PT}}}{L_{\mathrm{PT}}}\left(z_{\mathrm{PT}, \mathrm{u}}^{2}+z_{\mathrm{PT}, \mathrm{d}}^{2}\right) \theta_{\mathrm{T}}}{1+\frac{1}{\alpha_{\mathrm{sc}}}}-N_{\mathrm{Ed}, \mathrm{G}} \frac{b}{2}\right]
$$

$$
\kappa \leq 1-\frac{E_{\mathrm{PT}} \cdot z_{\mathrm{PT}, \mathrm{u}} \cdot \theta_{\mathrm{T}}}{f_{\mathrm{y}, \mathrm{PT}} \cdot L_{\mathrm{PT}}}=\kappa_{\text {max }}
$$

$$
\kappa \geq \frac{E_{\mathrm{PT}} \cdot z_{\mathrm{PT}, \mathrm{d}} \cdot \theta_{\mathrm{T}}}{f_{\mathrm{y}, \mathrm{PT}} \cdot L_{\mathrm{PT}}}=\kappa_{\text {min }}
$$

where $M_{\mathrm{T}}=M_{\mathrm{N}, \mathrm{Rd}} \gamma_{\mathrm{T}}$ is the moment at the target rotation that through the safety coefficient $\gamma_{\mathrm{T}}$ protects the column from yielding, while $\alpha_{\mathrm{sc}}=M_{\mathrm{E}} / M_{\mathrm{FD}}$ is a design parameter that control the self-centering capabilities of the column. $A_{\mathrm{PT}}$,

$223 L_{\mathrm{PT}}$ and $\kappa$ are the design variables of the problem and are respectively the area, the length, and the stress ratio of the

224 post-tensioned strands (i.e., $\kappa=\sigma_{\mathrm{PT}} / f_{y, \mathrm{PT}}$ where $\sigma_{\mathrm{PT}}$ and $f_{\mathrm{y}, \mathrm{PT}}$ are respectively the stress and the yield stress of the 225 strands) that allows definition of the value of the initial post-tensioning force. Once the area of the PT strands, $A_{\mathrm{PT}}$, is 
selected, Eq. (10) is used to define the initial stress ratio of the post-tensioning strands, $\kappa$, as well as their length, $L_{\mathrm{PT}}$,

227 in order to meet the design requirements, i.e., to limit the maximum moment at the design rotation $\theta_{\mathrm{T}}$ and to provide self-centering capability. At the same time, Eqs. (11) and (12) constrain the range of values for $\kappa$ and $L_{\mathrm{PT}}$ such that the limit states defined for the strands, i.e., yielding (corresponding to $\kappa_{\max }$ ) and loss of post-tensioning force (corresponding to $\kappa_{\min }$ ) in the strands, are reached for rotations equal, or higher, than the design rotations $\theta_{\mathrm{T}}$. More details on the design procedure are provided by Freddi et al (2017).

232 Considering 7 wire strands of $9.3 \mathrm{~mm}$ with an equivalent area of $A_{\mathrm{PT}}=52 \mathrm{~mm}^{2}$, Fig. 6(a) shows the variation of $\kappa$ 233 with respect to $L_{\mathrm{PT}}$. The coefficients $\gamma_{\mathrm{T}}$ and $\alpha_{\mathrm{sc}}$ were assumed equal to 1.165 and 1.10 , respectively. Any pair of $\kappa$ and $234 L_{\mathrm{PT}}$ with values within the highlighted 'acceptable zone' can be selected. However, the optimum design is the one that satisfies the design criteria and minimizes the length of the PT bars, and hence, is the one that is graphically identified by the 'Design point' in Fig. 6(a). The design procedure provided an $L_{\mathrm{PT}}$ equal to $805 \mathrm{~mm}$ and $\kappa$ equal to 0.2175 . The latter corresponds to a $T_{\mathrm{PT}}$ equal to $21.3 \mathrm{kN}$. In this case, the rotations $\theta_{\mathrm{PT}, \mathrm{u,y}}$ and $\theta_{\mathrm{PT}, \mathrm{d}, \mathrm{f}}$ are equal to $0.0306 \mathrm{rad}$ and 0.0302 rad, respectively. Fig. 6(b) shows the moment-rotation behavior for the column base gap opening mechanism.
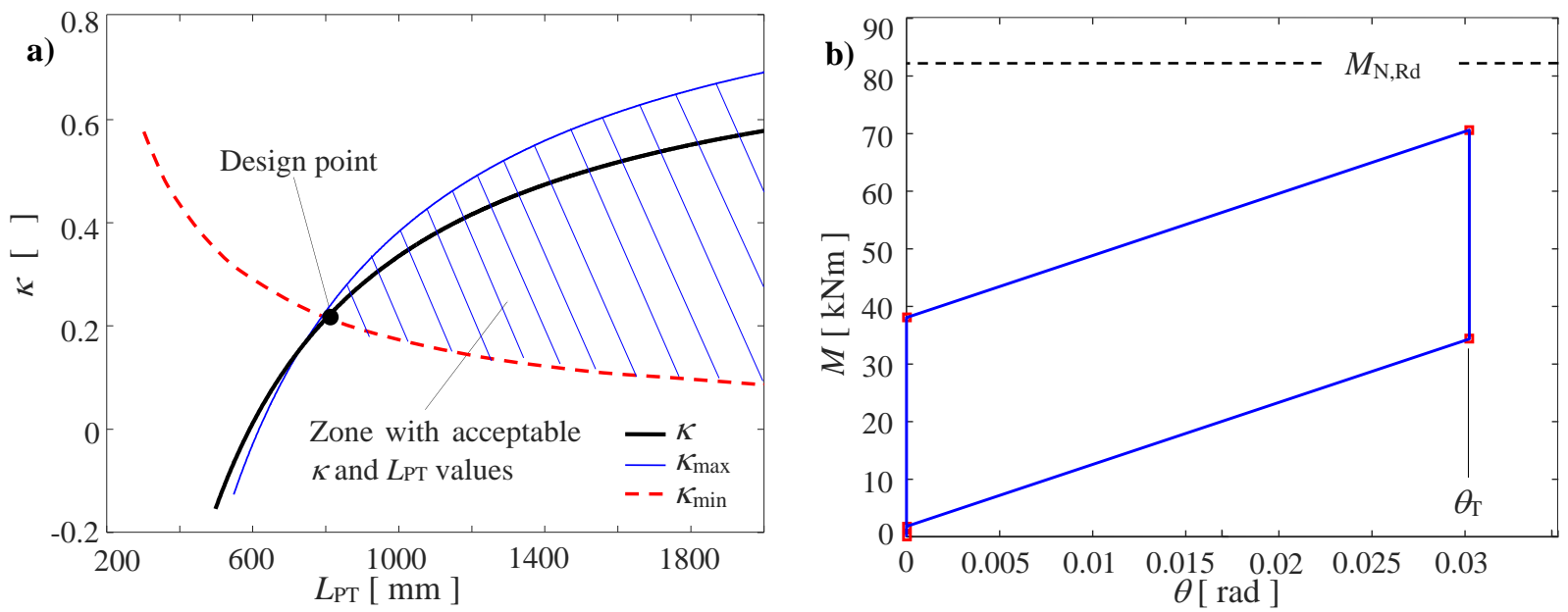

244 Fig. 6. (a) Variation of $\kappa$ with respect to $L_{\mathrm{PT}}$ for $A_{\mathrm{PT}}=52 \mathrm{~mm}^{2}$ and (b) moment-rotation behavior of the column base 
Once the strands were designed, $M_{\mathrm{FD}}$ was derived by $M_{\mathrm{E}}$ and $\alpha_{\mathrm{sc}}$ and then the FDs could be designed by selecting appropriate values of the parameters in Eq.s (4) and (5). FDs were introduced on the four sides of the column base,

248 and the relevant dimensions were $b_{\mathrm{FD}}=465 \mathrm{~mm}$ and $h_{\mathrm{FD}}=250 \mathrm{~mm}$. Hence, the required friction force in each friction 249 surface of the four FDs obtained by Eq. (5) was $F_{\mathrm{FD}}=10.87 \mathrm{kN}$. The thickness of the internal and external plates of the FDs were $10 \mathrm{~mm}$ and $8 \mathrm{~mm}$, respectively. Two $3 \mathrm{~mm}$ thick brass plates were used as friction interfaces, and two M12 class 10.9 bolts were used to apply the pre-loading force by tightening. The friction coefficient at the brass-steel interface was evaluated by preliminary tests described in Section 5. Successively, the pre-loading force was defined

253 based on the friction coefficient to achieve the required friction force. The dimensions of the slotted holes were rad). Fig. 7 summarizes the geometry of the column base.
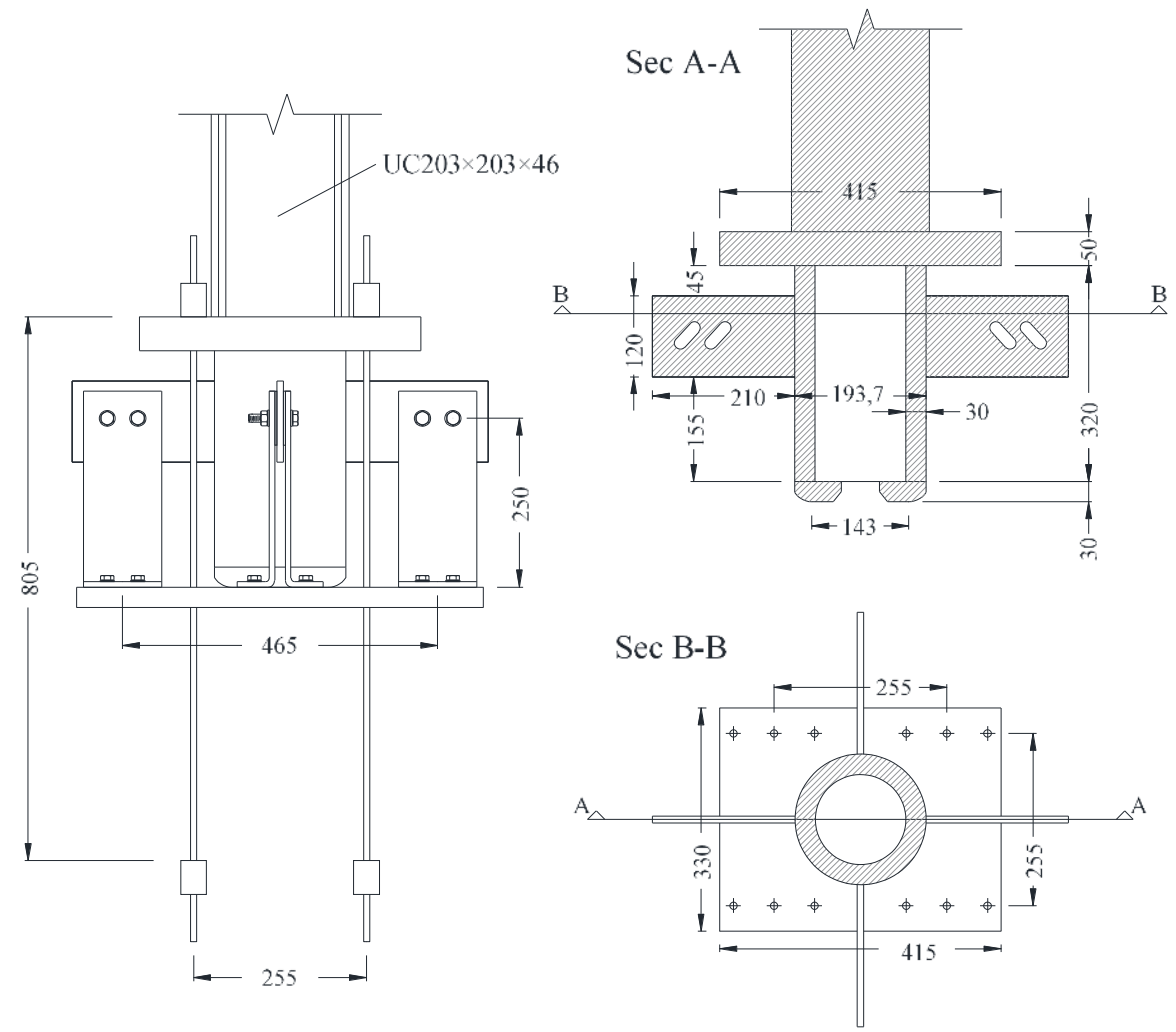

257

Fig. 7. Geometry of the specimen (dimensions in $\mathrm{mm}$ )

\section{INSTRUMENTATION}

Details of the friction devices

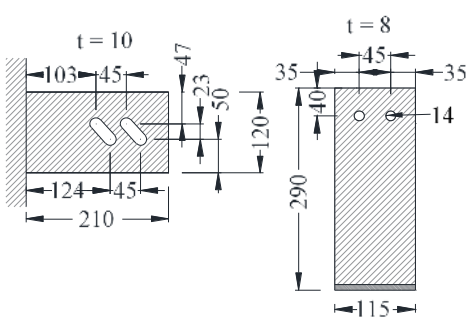

Dimensions of the slotted holes

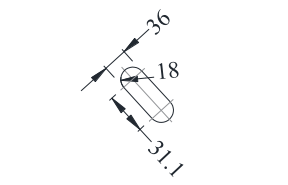

Base plate and shear key \& interaction $n$

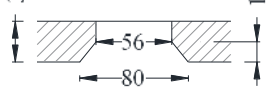

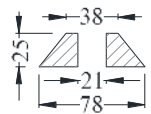
Amongst others, hydraulic jacks, load cells, linear variable differential transformer (LVDT), strain gauges and a torque 
wrench have been used during the tests. Specifications of the hydraulic jacks and load cells are listed in Table 3 and

263 Table $4.10 \mathrm{~mm}$ linear strain gauges with mild steel compensation have been employed, while the Norbar PRO 100

$2641 / 2 "$ torque wrench with a min and max torque of 20 and $100 \mathrm{Nm}$ has been used to control the tightening of the bolts.

265 In addition, the universal testing machine DARTEC 9500 have been used for the characterization tests of the FDs and

266 for the coupon tests of the steel materials. Data acquisition and tests management have been performed in LabView.

Table 3. Hydraulic jacks employed in the tests

\begin{tabular}{llllll}
\hline Actuators & \multirow{2}{*}{ Acronym } & Use & $\begin{array}{l}\text { Max force } \\
{[\mathrm{kN}]}\end{array}$ & $\begin{array}{l}\text { Stroke } \\
{[\mathrm{mm}]}\end{array}$ & $\begin{array}{l}\text { Weight } \\
{[\mathrm{kg}]}\end{array}$ \\
\hline Servocon System & & Application of the horizontal force & \pm 250 & \pm 150 & \\
Hi-Force HHS102 & HJA & Post-tensioning of strands & +110 & +50 & 3 \\
Yale YCS 57-70 & HJB & Post-tensioning of PT bars & +567 & +70 & 25 \\
\hline
\end{tabular}

Table 4. Load cells employed in the tests

\begin{tabular}{llll}
\hline Load Cells & Acronym & Measuring & $\begin{array}{l}\text { Max force } \\
{[\mathrm{kN}]}\end{array}$ \\
\hline Novatech F207 & LCA & Axial force in the bolts of the FDs & +80 \\
Novatech F313 & LCB & Axial force in the 7 wire strands $(9.3 \mathrm{~mm})$ & +200 \\
Novatech F203 & LCC & Axial force in the PT bars $(15 \mathrm{~mm})$ & +600 \\
\hline
\end{tabular}

\section{CHARACTERIZATION OF THE FRICTION DEVICES}

271 The friction force, $F_{\mathrm{FD}, \mathrm{i}}$, of each friction surface is given by Eq. (4) and is affected by the bolts pre-loading force, $N_{\mathrm{b}}$,

272 and the friction coefficient of the brass-steel interface, $\mu_{F D}$. The preliminary tests described in this section allowed to

273 characterize the FDs parameters to gain confidence in: $i$ ) the definition of the bolts pre-loading force, $N_{\mathrm{b}}$, used in the 274 tests and $i i)$ the definition of the friction coefficient, $\mu_{\mathrm{FD}}$, for the interface materials.

\section{$275 \quad 5.1$ Relationship between torque and the bolt pre-loading force}

276 The bolts pre-loading force can be determined from the tightening torque by the following equation

$$
N_{\mathrm{b}}=\frac{T_{\mathrm{b}}}{\alpha \cdot d}
$$

278 where $T_{\mathrm{b}}$ is the value of the tightening torque, $d$ is the bolt diameter, and the recommended value of $\alpha$ is equal to 0.2

279 (Latour et al 2015). It was observed by previous studies that this relationship may under- or over-estimate the bolt

280 pre-loading force, $N_{\mathrm{b}}$, by $20 \%$ due to different bolt type and differences in temperature, humidity, thread conditions,

281 lubrication, etc. Hence, the characterization tests aimed at deriving the $\alpha$ parameter that best described the relationship

282 between the tightening torque $T_{\mathrm{b}}$ and bolt pre-loading force, $N_{\mathrm{b}}$, for the M12 bolts Class 10.9 used in the tests. 
284 The tightening torques were applied by a Norbar torque wrench, while the bolt's pre-loading force was measured with 285 load cells (LCA in Table 4). Fig. 8(a) shows the test setup, while Fig. 8(b) shows the experimental results. Regression 286 of a total of 270 samples provided a value for $\alpha$ equal to 0.1743 .

a)

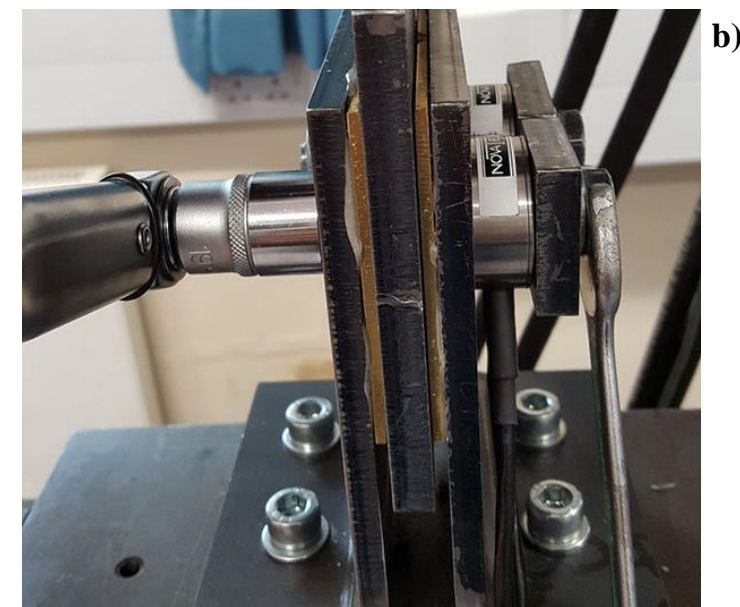

b)

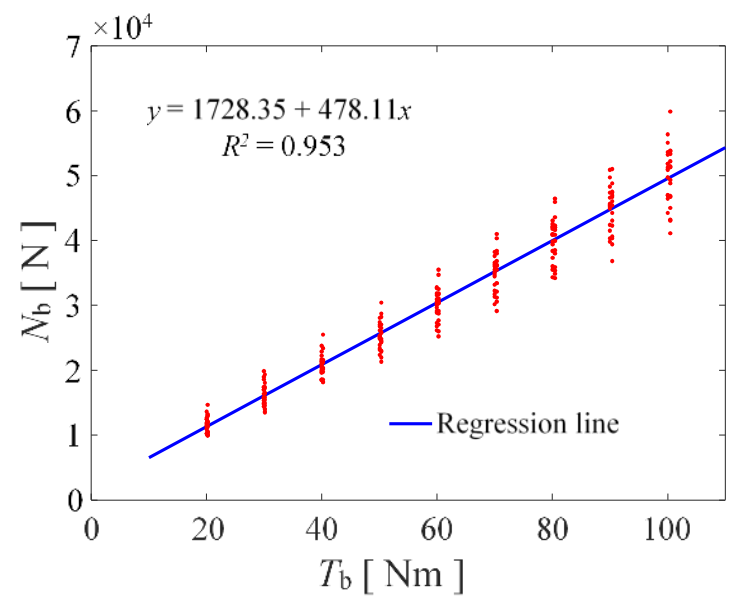

Fig. 8. Characterization test for the friction devices (FDs). Relationship between the tightening torque $T_{\mathrm{b}}$ and the bolt pre-loading force $N_{\mathrm{b}}$. (a) Representation of the tests' setup; (b) test results and interpolation curve

\subsection{Tests for the friction coefficient of the materials interface}

This part of the study provided the static and kinetic friction coefficient of the brass-steel interface, $\mu_{F D}$, allowing also the evaluation of its variability during the cyclic displacement histories. To allow for relative displacements between the plates in the friction surfaces and to accommodate the travel path of the bolts, the inner plate of the FD, had slotted holes with dimensions of 44 by $15 \mathrm{~mm}$ as shown in Fig. 9(a). The two outer steel plates and the inner brass friction plates in Fig. 9(b) and (c) had circular holes and were glued together with Araldite Epoxy Adhesive. The clamping force was applied by two M12 bolts 10.9 class and the holes were of $14 \mathrm{~mm}$, leaving extra tolerance with respect to the recommendations of the Eurocode 3 (EN 1993-1-8 2005). The dimensions of the friction surfaces were the same as for the FDs used in the tests of the column base. The brass material was ' $\mathrm{C} 46400$ half hard', while the material used for the steel components was S355.

Quasi-static tests were performed using the configuration showed in Fig. 10 and were carried out under 20 loading cycles with a linear variation of the displacement, a constant amplitude of $\pm 10 \mathrm{~mm}$, and a frequency equal to $0.25 \mathrm{~Hz}$ as shown in Fig. 12. Fig. 11(a) shows two instants during the test that correspond to the maximum and minimum displacements, while Fig. 11(b) and (c) show, respectively, the internal plate with slotted holes and one brass plate after the test. Four tests were conducted for different levels of pre-loading force, i.e., starting from $10 \mathrm{kN}$ up to $25 \mathrm{kN}$, 

was monitored with load cells (LCA in Table 4).

a)

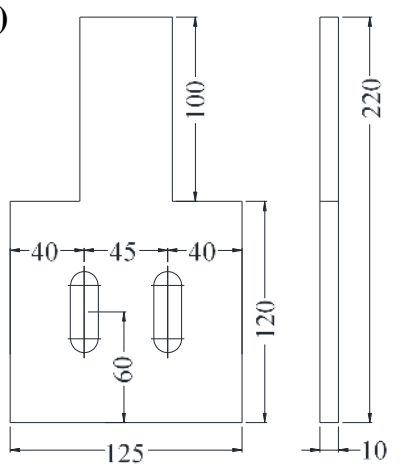

b)
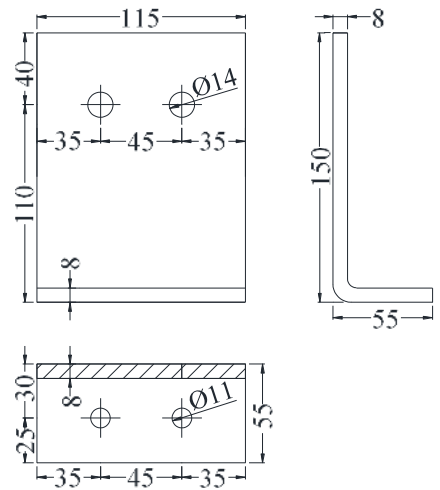

c)

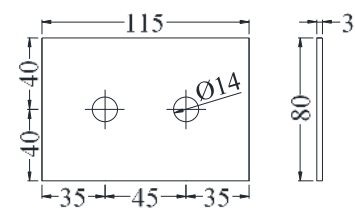

Fig. 9. Characterization test for the friction devices (FDs). Friction coefficient. (a) Internal plate with slotted holes; (b) external plate and (c) brass plate (dimensions in $\mathrm{mm}$ )
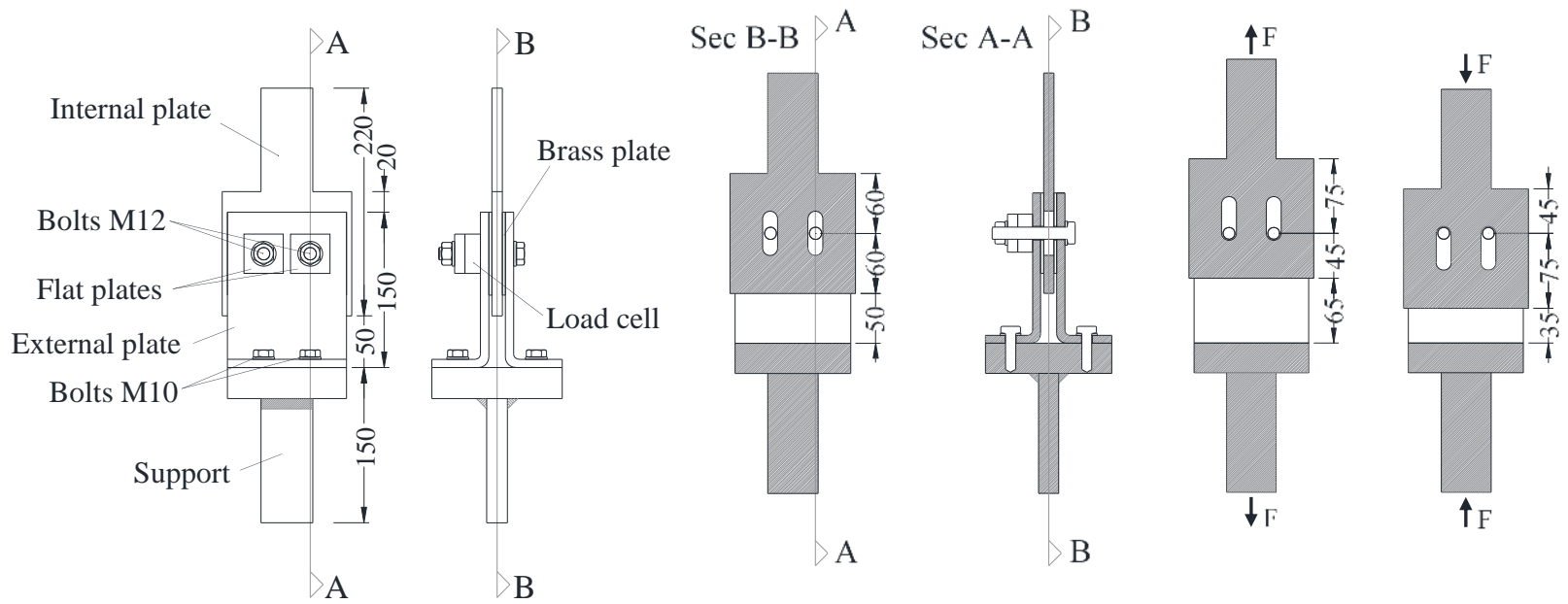

Fig. 10. Characterization test for the friction devices (FDs). Friction coefficient. Dimensions under the maximum and 310 minimum displacement configuration (dimensions in $\mathrm{mm}$ )

a)

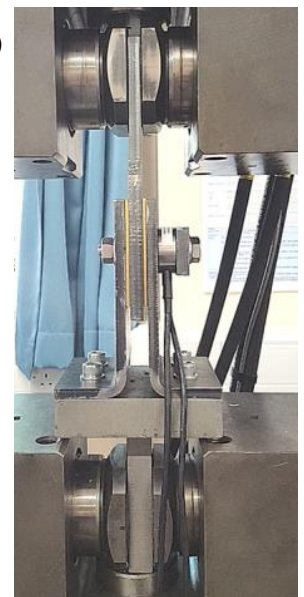

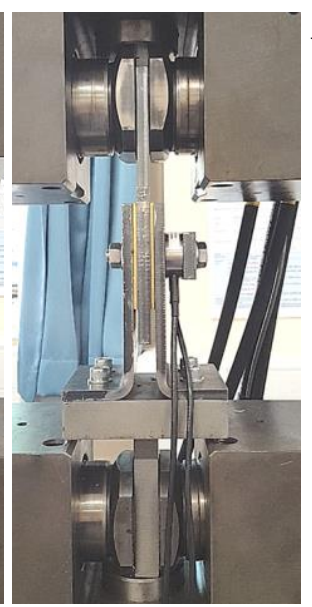

b)

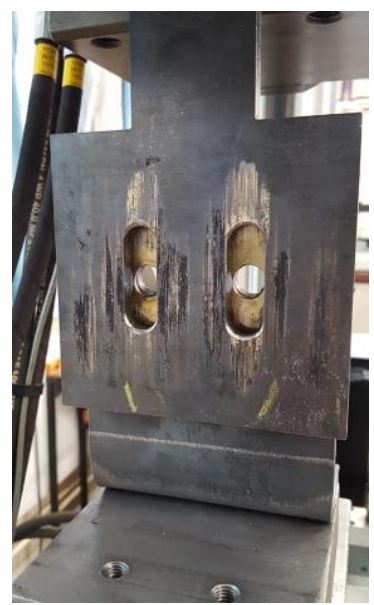

c)

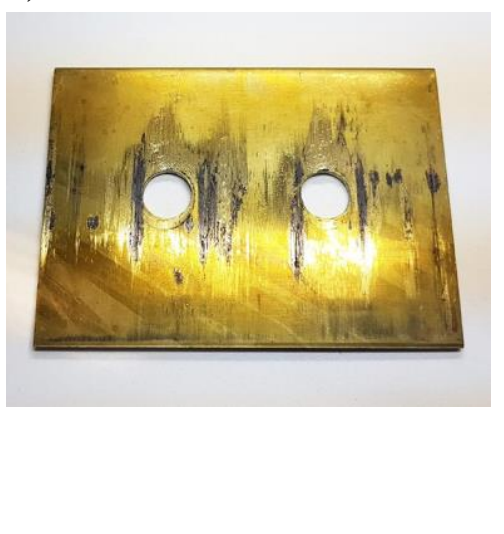

Fig. 11. Characterization test for the friction devices (FDs). Friction coefficient. (a) Front view with maximum and 
The friction coefficient was determined by

$$
\mu_{\mathrm{FD}}=\frac{F_{\mathrm{FD}}}{m \cdot n \cdot N_{\mathrm{b}}}
$$

316 where $m=2$ is the number of surfaces in contact, $n=2$ is the number of bolts, $N_{\mathrm{b}}$ is the bolt pre-loading force while

$317 \quad F_{\mathrm{FD}}$ is the sliding force. The results of Fig. 12 and Fig. 13 refer to the test with the bolts' pre-loading force equal to 15

318 kN. Fig. 12(a) shows the displacement and force history, respectively, for the whole duration of the test, while Fig.

319 12(b) shows the results for the cycle from 50 to 56 seconds. Fig. 13(a) shows the force-displacement response that,

320 considering the average normal force acting on the friction interface during the whole load history, which is equal to

$32133.47 \mathrm{kN}$, allowed to derive Fig. 13(b) which shows the friction coefficient according to Eq. (14).

322 Fig. 13(a) shows the force-displacement behavior exhibiting a slight kinematic hardening similarly to what was

323 observed by Latour et al (2015). This is due to the changes in the contact surfaces, which were initially smooth. During

324 sliding motion, the number of asperities increased due to the high contact pressures and to the wearing of the brass,

325 causing an increase in interlocking friction components in the final surface, as shown in Fig. 11(b) and (c). Fig. 13(a)

326 shows an increase of the friction coefficient that, after a few cycles, become stable with an increased sliding force of 327 the order of $10 \%$ with respect to the force corresponding to the first sliding. Consistent results were obtained for the 328 other pre-loading forces and the average value of the friction coefficient, $\mu_{\mathrm{FD}}$, was equal to 0.25 . It is important to 329 highlight that for the pre-loading force of $25 \mathrm{kN}$, debonding of the external plate with the interface plate was observed.

330 For this reason, a limited value of the bolts pre-loading force was used in the full-test of the column base as described 331 in Section 7.
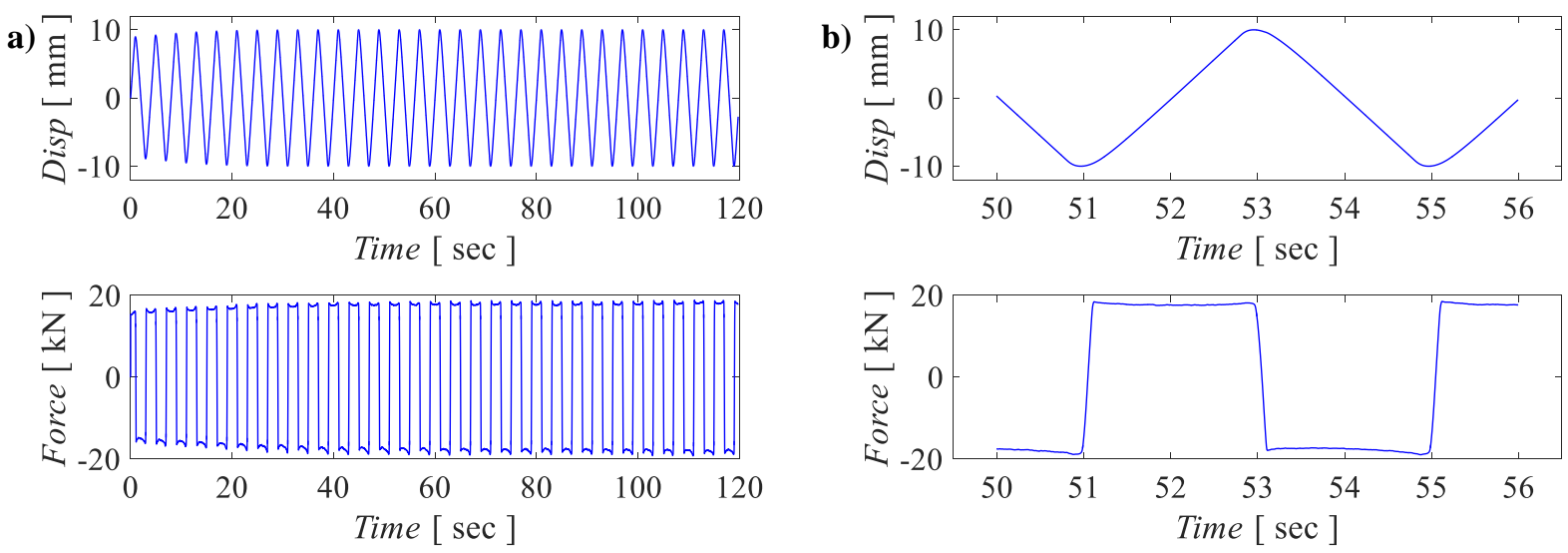

332 Fig. 12. Characterization test for the friction devices (FDs). Displacement and force history of the friction device (FD) 333 test with pre-loading force in each bolt of $15 \mathrm{kN}$ 

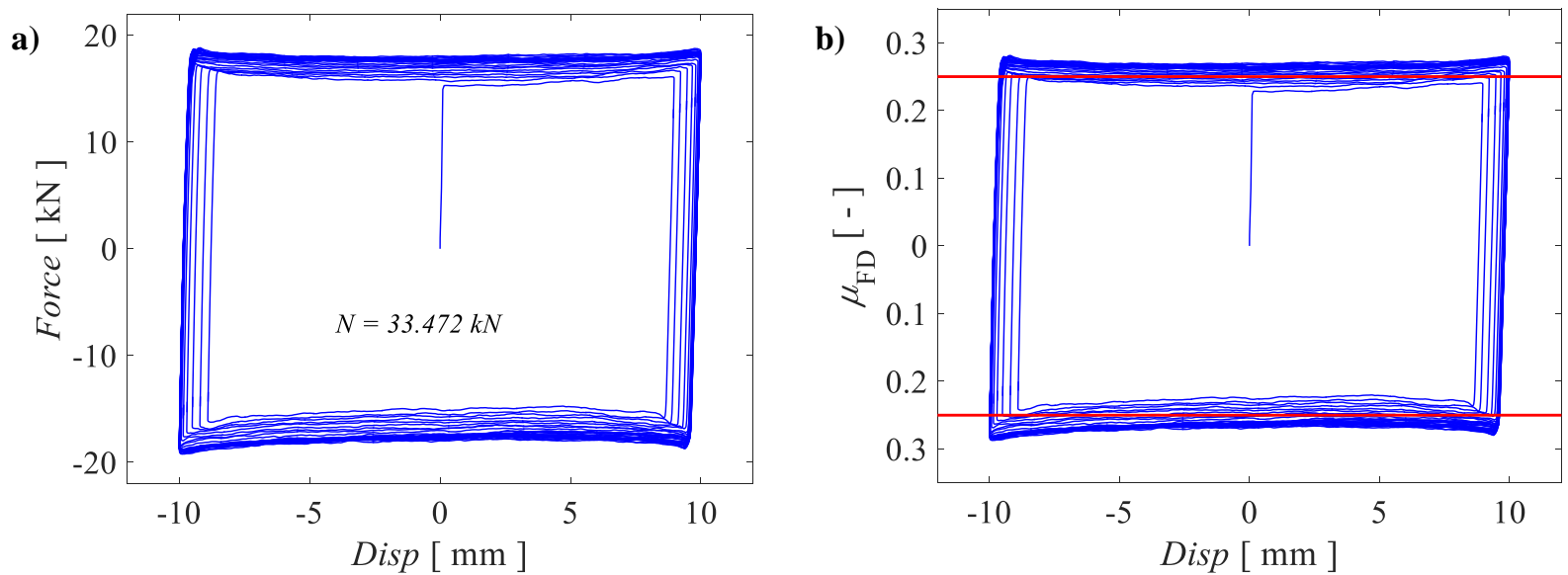

334 Fig. 13. Characterization test for the friction devices (FDs). Initial pre-loading force in each bolt of 15kN. (a) Forcedisplacement hysteretic curve and (b) normalized force for the definition of the friction coefficient $\mu_{\mathrm{FD}}$

\section{COUPON TESTS}

338 The elements experiencing stresses beyond their yield stress (for rotations larger that the $\theta_{\mathrm{T}}$ ) included the posttensioned strands and the FDs. Certificates for the strands' stress-strain behavior were available from the supplier. For

340 the characterization of the material properties of the plates of the FDs, coupon tests were performed using of the

341 universal testing machine DARTEC 9500. Three coupon specimens for the FDs' plates were subjected to tensile tests

342 according to the EN ISO 6892-1 (2009). Specimen strains were measured using an axial extensometer. Average values

343 of the properties of the steel for each component are listed in Table 5.

344 Table 5. Steel Properties

\begin{tabular}{cccccc}
\hline Test & $\begin{array}{c}\text { Yield Stress } \\
{[\mathrm{MPa}]}\end{array}$ & $\begin{array}{c}\text { Yield Strain } \\
{[\%]}\end{array}$ & $\begin{array}{c}\text { Young Modulus } \\
{[\mathrm{MPa}]}\end{array}$ & $\begin{array}{c}\text { Tensile Strength } \\
{[\mathrm{MPa}]}\end{array}$ & $\begin{array}{c}\text { Maximum } \\
\text { Elongation } \\
{[\%]}\end{array}$ \\
\hline 1 & 335 & 0.166 & 201807 & 467 & 31.5 \\
2 & 327 & 0.165 & 198181 & 452 & 32.7 \\
3 & 332 & 0.164 & 202439 & 457 & 30.2 \\
Average Values & 331.3 & 0.165 & 200809 & 458.6 & 31.47 \\
\hline
\end{tabular}

\section{EXPERIMENTAL TEST ON THE ROCKING COLUMN BASE}

\subsection{Test setup and instrumentation}

348 The proposed column base was tested by using the test setup shown in Fig. 14 and illustrated in the photos of Fig. 15.

349 The test setup was designed based on the space available in the lab and on the strong floor connections that were 350 placed as a square wire every $406.4 \mathrm{~mm}$. 
352 Two external Dywidag PT bars with diameter of $15 \mathrm{~mm}\left(A_{\mathrm{PT}, \mathrm{ext}}=177 \mathrm{~mm}^{2}\right.$; diameter after thread of $\left.17 \mathrm{~mm}\right)$ and yield 353 and ultimate stresses equal to $f_{\mathrm{y}, \mathrm{PT}, \mathrm{ext}}=900 \mathrm{MPa}$ and $f_{\mathrm{u}, \mathrm{PT}, \mathrm{ext}}=1100 \mathrm{MPa}$, were used to simulate the axial forces due to 354 gravity loads. The parameters affecting the stiffness of the PT bars were the free length and the Young's modulus, which were equal to $L_{\mathrm{PT}, \text { ext }}=1826.9 \mathrm{~mm}$ and $E_{\mathrm{PT} \text {,ext }}=205000 \mathrm{MPa}$. The PT bars were connected at one end to the upper beam, which transfers the force to the column, and at the other end to two anchor supports connected to the strong floor. Hollow hydraulic jacks type B (HJB in Table 3, in Fig. 14 and Fig. 16(a)) were used to apply the posttensioning force. The load cells type C (LCC 1 and 2 in Table 4, in Fig. 14 and Fig. 16(b)) were used to calibrate the initial force and to measure its variation during the tests. After post-tensioning through the hydraulic jacks, intermediate bolts, as shown in Fig. 16(a), were placed and tightened to the web of the upper beam to avoid loss of PT force as consequence of the loss of pressure in the hydraulic jacks. The design initial PT force for the external bars was equal to $96.3 \mathrm{kN}$. During the rocking, the uplift of the column base produced an increase of the tension force of the PT bars which was measured during the test.

364 In addition to the axial force imposed by the PT bars, the total force was increased by the weight of all the 365 components of the specimen and of the test setup. The weight of the upper beam and the column were respectively 366 equal to $175 \mathrm{~kg}$ and $180 \mathrm{~kg}$, while the total weight was equal to $430 \mathrm{~kg}$. This value does not account for half of the 367 weight of the horizontal actuator and hinges that was equal to $130 \mathrm{~kg}$.

\subsection{Steel basement and post-tensioned strands}

369 The column was placed on a steel basement, which included the anchor plates for the strands as shown in Fig. 14, Fig. $37016(\mathrm{c})$ and (e). The strands were fixed to the anchor plate of the steel basement from one side, and post-tensioned 371 through hollow hydraulic jacks type A (HJA in Table 3, in Fig. 14 and Fig. 16(g)), which were supported by the anchor 372 plate of the column base on the other side. Similar to the external PT bars, the strands were fixed to the upper anchor 373 plate by the intermediate anchor grips to avoid loss of PT force. This was made possible thanks to the supports shown 374 in Fig. 14 and Fig. 16(g). The design PT force for the strands was equal to $21.3 \mathrm{kN}$. The anchor grips were composed 375 by wedges coupled with open barrels as showed in Fig. 16(d). Four load cells type B (LCB in Table 4, in Fig. 14 and 376 Fig. 16(e)) were located between the anchor grips and the anchor plates in the steel basement to calibrate the initial 377 post-tensioning force in the strands and to measure force variations during the tests. The upper plate of the steel 378 basement was provided with oversized holes so that the strands were free to move laterally during the column rocking. 
379 In addition, the upper plate included threaded holes for the connection of the FDs and the shear key. Fig. 16(c) shows

380 the shear key fixed to the steel basement.

\subsection{Friction devices}

382 Each external plate of the FDs was bolted to the steel basement with two M10 bolts. The FDs had the same 383 configuration used in the characterization tests with the only exception that the internal plates had inclined slotted 384 holes to accommodate the bolts travel path. The internal plates were welded to the column as shown in Fig. 16(h) and

385 (i). Four load cells type A (LCA in Table 4, Fig. 14 and Fig. 16(h)) were used to measure the variation of the axial 386 force in four of the eight bolts of the FDs.

387 According to the original design, the bolts' pre-loading force in the friction devices was equal to $21.74 \mathrm{KN}$. This

388 required a tightening torque equal to $T_{\mathrm{b}}=45.47 \mathrm{Nm}$. However, to avoid the debonding of the brass plates, that was 389 observed in the FDs' characterization tests, and which could jeopardize the full-scale tests, the bolts' pre-loading force 390 was set to $10 \mathrm{kN}$ by applying a tightening torque, $T_{\mathrm{b}}$, of $20.92 \mathrm{Nm}$.

\section{$391 \quad 7.5$ Other components}

392 LVDTs 1 to 4 , as shown in Fig. 14 and Fig. 16(g), were placed in the column base at different heights in order to 393 measure the horizontal translations, rotations in the longitudinal direction, as well as, the horizontal translations in the 394 transverse direction and torsions. Moreover, in order to evaluate the stresses and deformation of the circular hollow 395 cylinder of the column base, two strain gauges at each side, were introduced in the position close to the pivot points 396 of the rocking as shown in Fig. 16(h). Finally, the specimen was connected with the horizontal actuator, which was

397 fixed to a steel strong frame as shown in Fig. 15. The actuator was connected at both the ends by hinges to avoid any 398 transfer of moment to the column. 

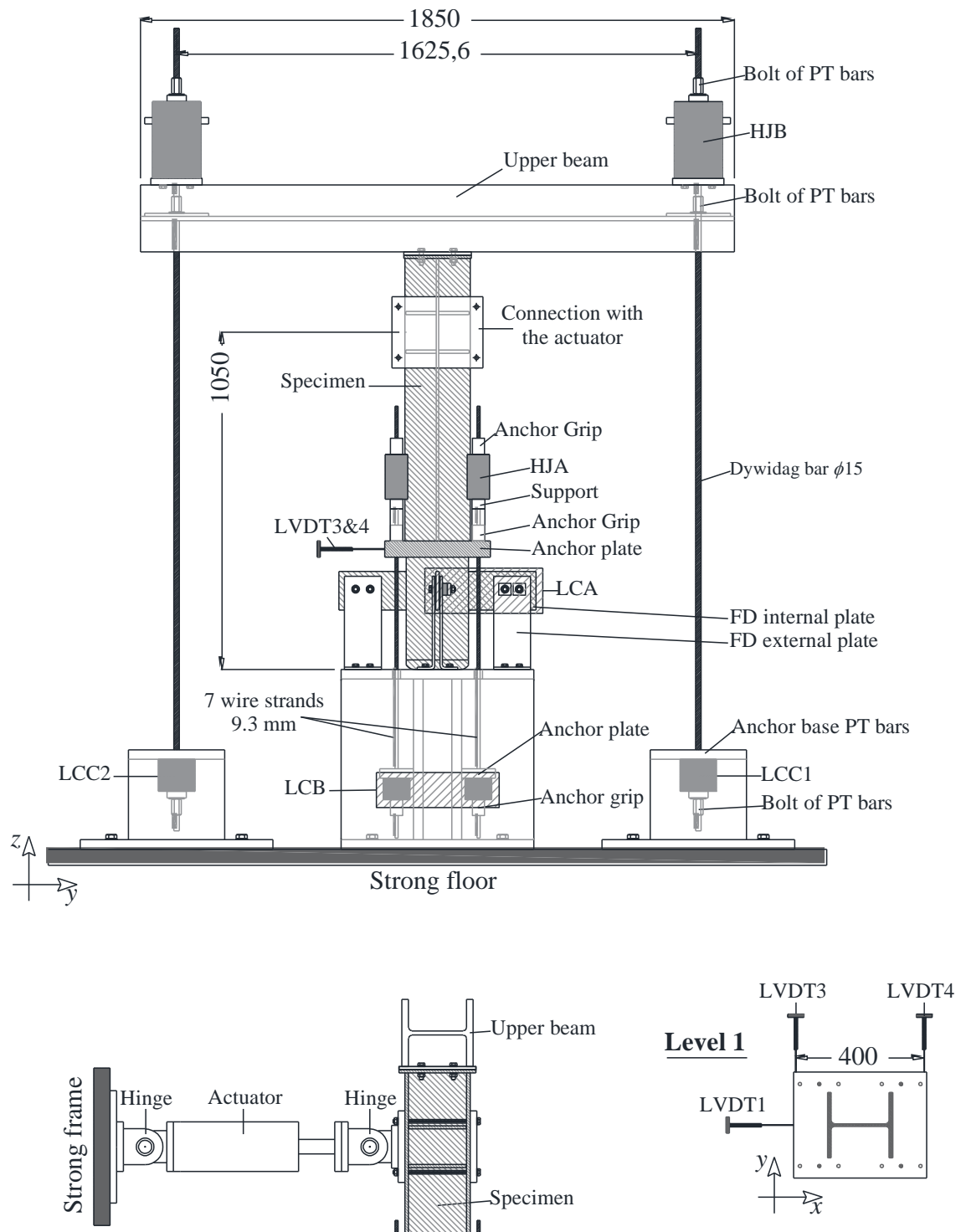
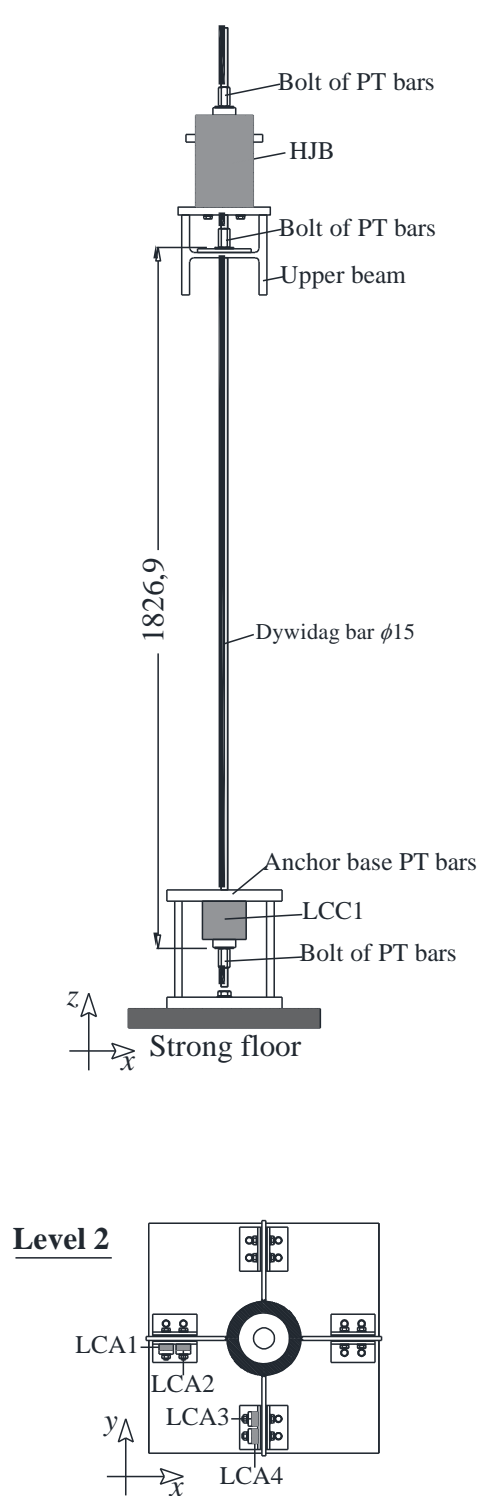

Level 3

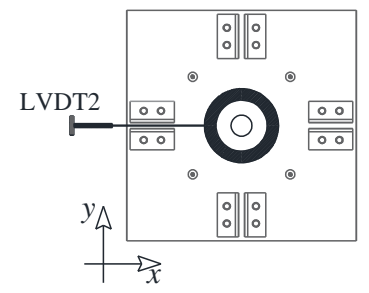

LCA - Load cell (Type A) LCB - Load cell (Type B) LCC - Load cell (Type C) $\underline{\text { Level } 4}$

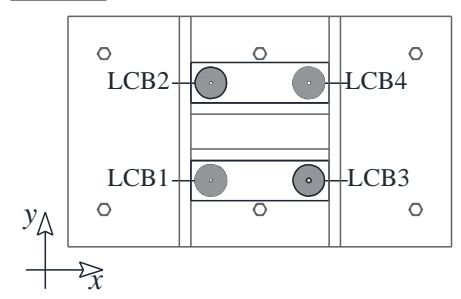

HJA - Hydraulic jack (Type A)

HJB - Hydraulic jack (Type B)

LVDT - Linear variable differential transformer 

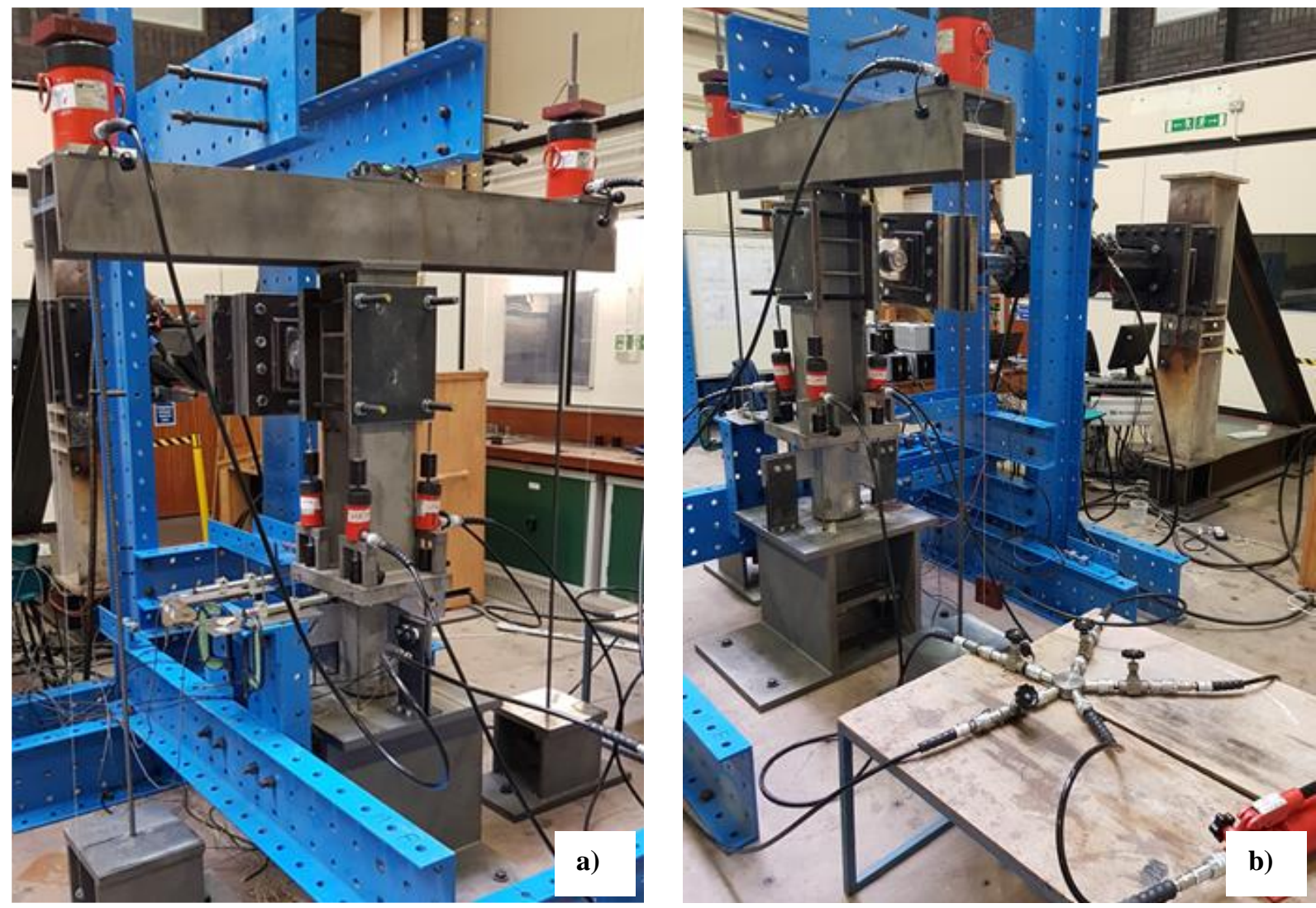

$401 \quad$ Fig. 15. Full-test setup

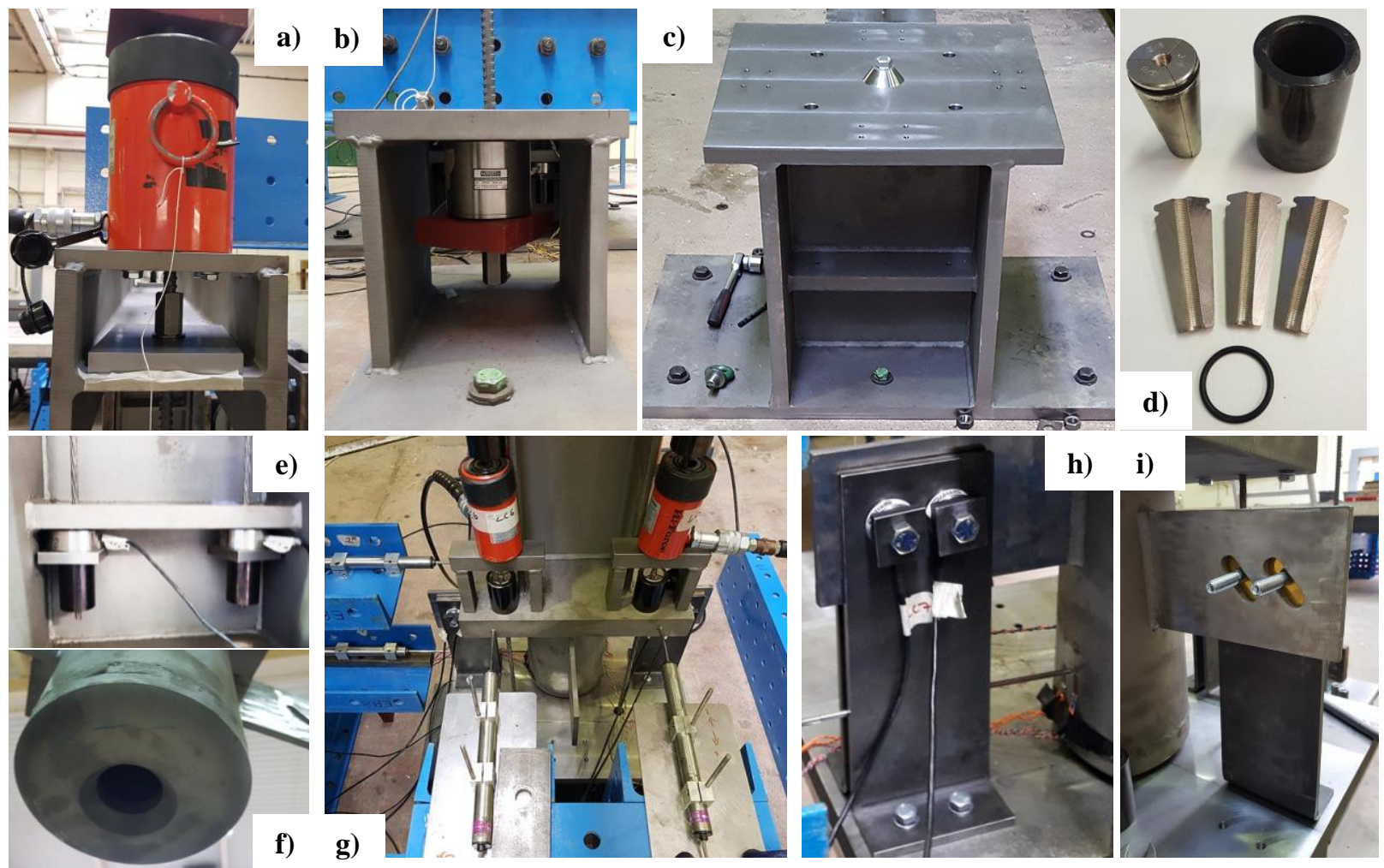

402 Fig. 16. Full-test setup components and instrumentation 


\section{EXPERIMENTAL RESULTS}

405 Quasi static cyclic tests were performed for different configurations that included different components of the column

406 base, i.e., PT bars for the axial force only (test type A); PT bars and strands only (test type B); PT bars, strands, and

407 FDs in the longitudinal direction only (test type C); and the complete column base (test type D), as indicated in Table

408 6. This allowed to experimentally decouple the moment contributions from each component. Preliminary tests were

409 performed with different amplitudes without overcoming the elastic behavior of the strands and up to the target design

410 rotation, $\theta_{\mathrm{T}}$. The results of these cyclic tests are shown, for all the tests' configurations, in Fig. 17 and Fig. 18.

411 Additionally, a final test with cyclic displacements of increasing amplitude was conducted showing the damage-free

412 behavior of the column base up to the target design rotation, $\theta_{\mathrm{T}}$ while for amplitudes higher than $\theta_{\mathrm{T}}$, yielding of the

413 strands occurred, and the failure of the FDs' plates due to bolts bearing was observed for very large rotations. The

414 results are shown in Fig. 20 and Fig. 21.

415

416

Table 6. Tests configurations

\begin{tabular}{cl}
\hline Test types & Components included \\
\hline A & PT bars \\
B & PT bars and PT strands \\
C & PT bars, PT strands and longitudinal FDs \\
D & PT bars, PT strands, longitudinal and transverse FDs \\
\hline
\end{tabular}

418 It is worth mentioning that, while the analytical formulation reported in Sections 2 and 3 considers only the rotation

419 related to the gap opening, the column base rotation observed during the test, and reported in the following part of the

420 paper, was measured based on the relative displacement of the LVDTs 1 and 2 divided by the distance between the

421 two and hence accounts also for the deformability of the test setup. Moreover, it is important to point out the difficulties

422 in applying the exact values of the initial forces in PT bars, strands, and bolts. However, these differences between the

423 designed column base and the one actually tested, do not affect the final outcomes of the experimentation. The applied

424 forces were measured in the experimental tests and FE models were successively adjusted to replicate the forces

425 measured during the tests to evaluate their ability to represent the experimental results. Similarly, the test setup was

426 included in the numerical model to account for its deformability. The numerical models were developed in ABAQUS

427 (2013) and are discussed in Section 9. 
430 Fig. 17 shows the experimental results for the cyclic test of column base type A for rotations up to about 0.045 rads. 431 Fig. 17(a) shows the moment-rotation curve, while Fig. 17(b) shows the tension force variation in the PT bars. 432 Similarly, Fig. 18 shows the experimental results for the cyclic test up to the target rotation $\left(\theta_{\mathrm{T}}=0.03\right.$ rads, $3 \%$ drift $)$ 433 for the column base types B, C, and D. Fig. 18(a) shows the moment-rotation curves where it can be observed the 434 elastic behavior of the column base type B and the influence of the FDs in dissipating energy. The small difference 435 between the curves $\mathrm{C}$ and D shows the low influence of the transverse FDs as consequence of their small displacement 436 and short lever arm with respect to the pivot point of rocking. However, their presence allows to dissipate the seismic 437 energy when the column is subjected to loads in a different direction. The small residual displacement was related to the imperfections of the coupling of the column base plate with the steel basement, as will be discussed in Section 9.

439 Fig. 18(b) shows the tension in the PT bars and as expected for these components, there is a superposition of the curves 440 for column base types B, C, and D. The same applies for the strands' tension force and the strain gauges' measurements, 441 as such, for simplicity, only the results of the column base type B are shown. Fig. 18(c) shows the tension force 442 variation in the strands. Their initial PT force was equal to $29.65 \mathrm{kN}$ with very small differences from strand to strand. 443 Their behavior was elastic and, the tension force showed different stiffness for negative and positive values of the 444 rotation due to the change of the pivot point when rocking which results in changes to the length of the lever arm. Fig. $44518(\mathrm{~d})$ shows the strain gauges measurements. Only strain gauges 1, 2, and 4 are shown since strain gauge 3 was 446 damaged during the test. The results show the compression and decompression of the column edge while rocking, 447 demonstrating the elastic behavior of the material.

a)

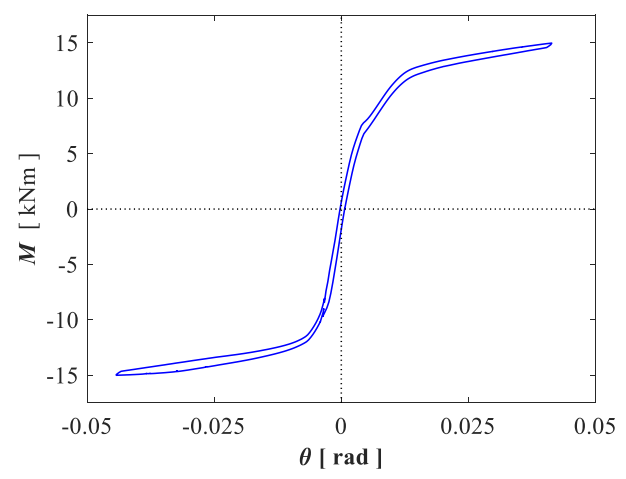

b)

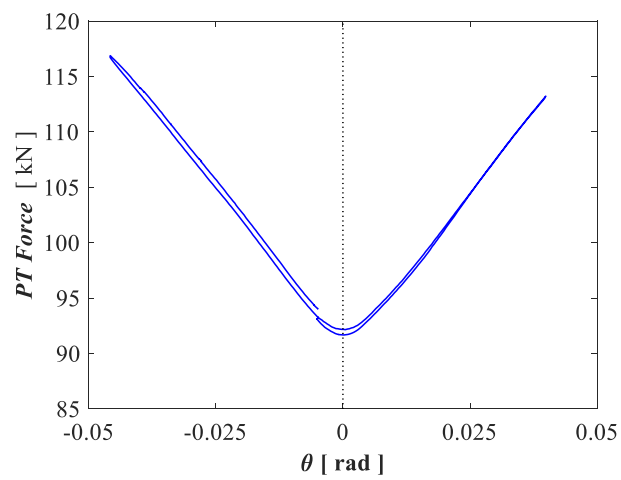

449 Fig. 17. Cyclic test of the column base type A. (a) Moment-rotation curve and (b) tension force in the PT bars 
a)

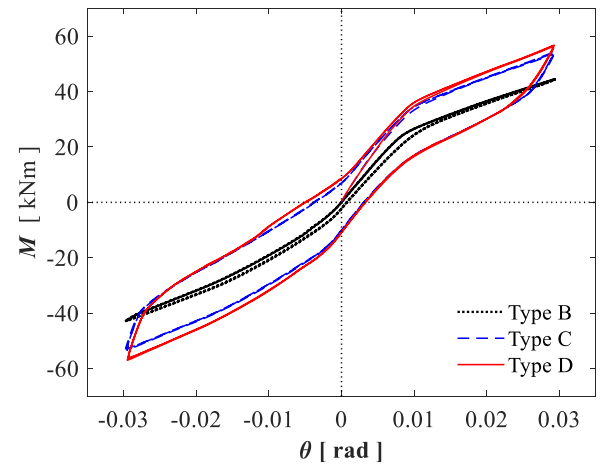

c)

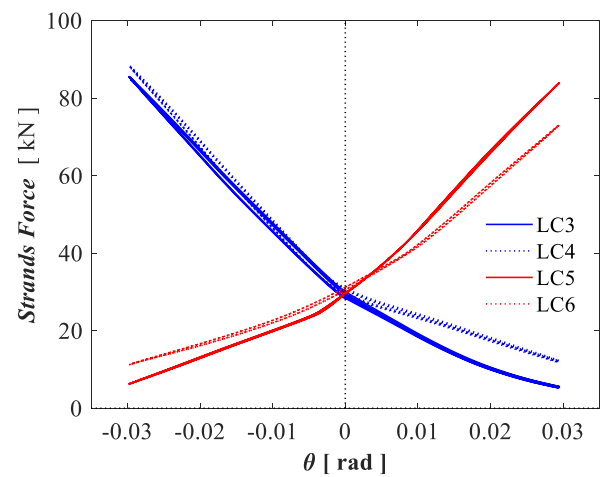

b)

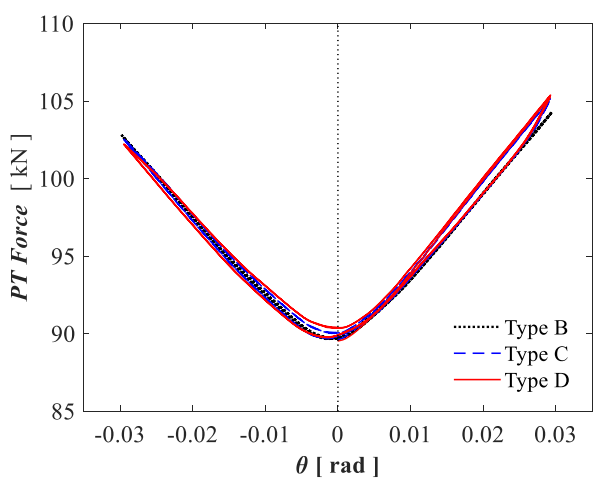

d)

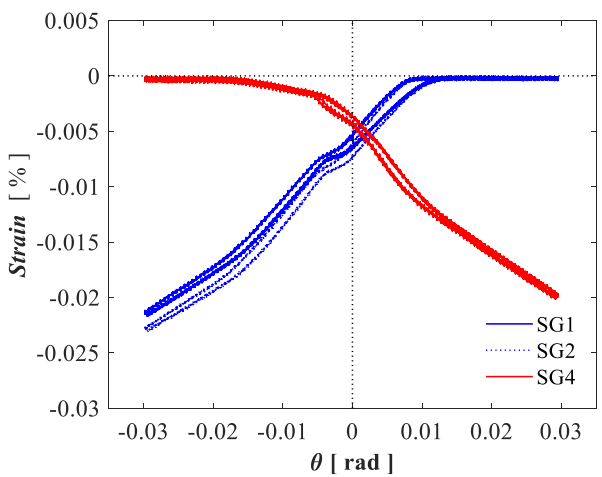

Fig. 18. Cyclic test of the column base types $B, C$ and $D$ up to the target rotation. (a) Moment-rotation curve; (b) PT bars tension force; (c) strands' tension force for the column base type B and (d) strain gauges' records the column base type B

\subsection{Final tests}

The final test was conducted on the complete column base (type D) with increasing amplitudes up to the first component's failure by using a loading protocol that complies with the test requirements of AISC 341-16 (2005) for 'link-to-column moment connections'. The load protocol consisted of cyclic lateral displacements with increasing amplitude imposed in a quasi-static fashion as reported in Table 7. The protocol included three initial sets of six cycles at $8.25,11$, and $16.5 \mathrm{~mm}$ displacements, four subsequent cycles at $22 \mathrm{~mm}$, and five sets of two cycles at 33, 44, 66, 88 and $100 \mathrm{~mm}$. The specimen was also monotonically pushed to a displacement equal to $150 \mathrm{~mm}$ to identify the failure mode. Fig. 19 shows two displacements configurations considering the column at the onset of rocking on the right and left edges respectively for rotations of 0.095 and 0.143 rads $(9.5 \%$ and $14.3 \%$ drift).

Fig. 20(a) shows the moment-rotation curves for cycle types from 1 to 5 with displacements amplitudes up to 33 mm (0.0314 rads, $3.14 \%$ drift) while Fig. 20(b) shows the moment-rotation curves for the whole test. Fig. 21 shows the results for the moment-rotation curves, tension in the PT bars, tension in the strands, measurements from the strain gauges, and tension force in the bolts independently for the cycle types from 1 to 5, 6 and 7 and from 8 to 10 . In this 
figure, together with the cycles in the displacement interval, the dotted black line shows also one cycle before and

469 after, providing a better representation of the results' variation.

470 The results shown in Fig. 20(a) are similar to what is observed in the preliminary tests and show the elastic and 471 damage-free behavior of the components up to the target rotation. Additional information provided by this final test

472 are related to the behavior of the column base for rotations beyond the target one, as shown in Fig. 20(b) and more in 473 detail in Fig. 21.

Table 7. Load protocol

\begin{tabular}{cllll}
\hline $\begin{array}{l}\text { Cycle } \\
\text { types }\end{array}$ & $\begin{array}{l}\text { Number of } \\
\text { cycles }\end{array}$ & $\begin{array}{l}\text { Amplitude } \\
{[\mathrm{mm}]}\end{array}$ & $\begin{array}{l}\text { Rotation } \\
{[\mathrm{rad}]}\end{array}$ & $\begin{array}{l}\text { Drift } \\
{[\%]}\end{array}$ \\
\hline 1 & 6 & 8.25 & 0.0078 & 0.78 \\
2 & 6 & 11 & 0.0105 & 1.05 \\
3 & 6 & 16.5 & 0.0157 & 1.57 \\
\hline 4 & 4 & 22 & 0.0210 & 2.10 \\
\hline 5 & 2 & 33 & 0.0314 & 3.14 \\
6 & 2 & 44 & 0.0419 & 4.19 \\
7 & 2 & 66 & 0.0629 & 6.29 \\
8 & 2 & 88 & 0.0838 & 8.38 \\
9 & 2 & 100 & 0.0952 & 9.52 \\
\hline 10 & Monotonic up to 150 mm & 0.1430 & 14.3 \\
\hline
\end{tabular}

a)

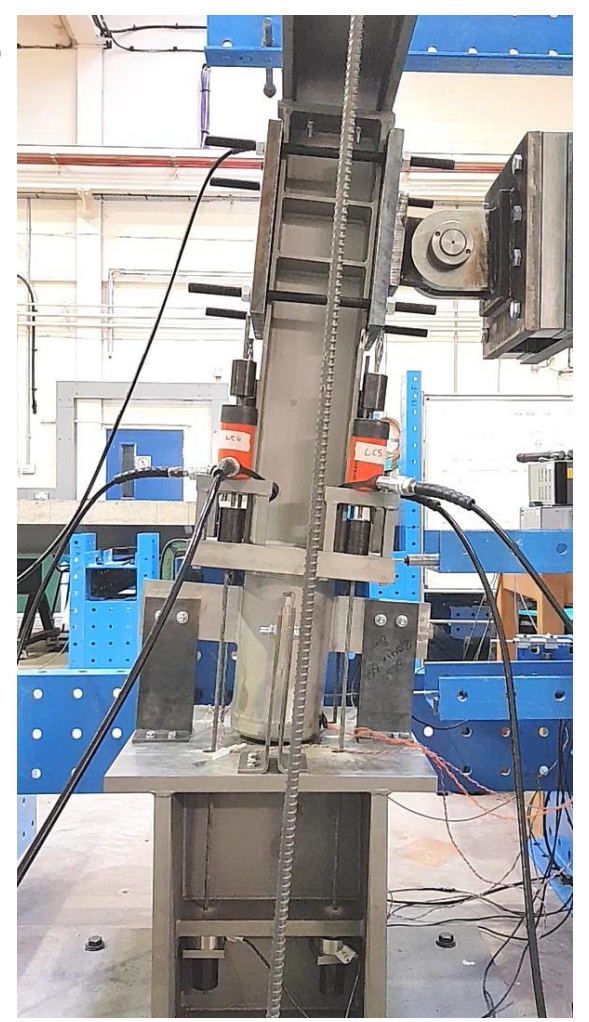

b)

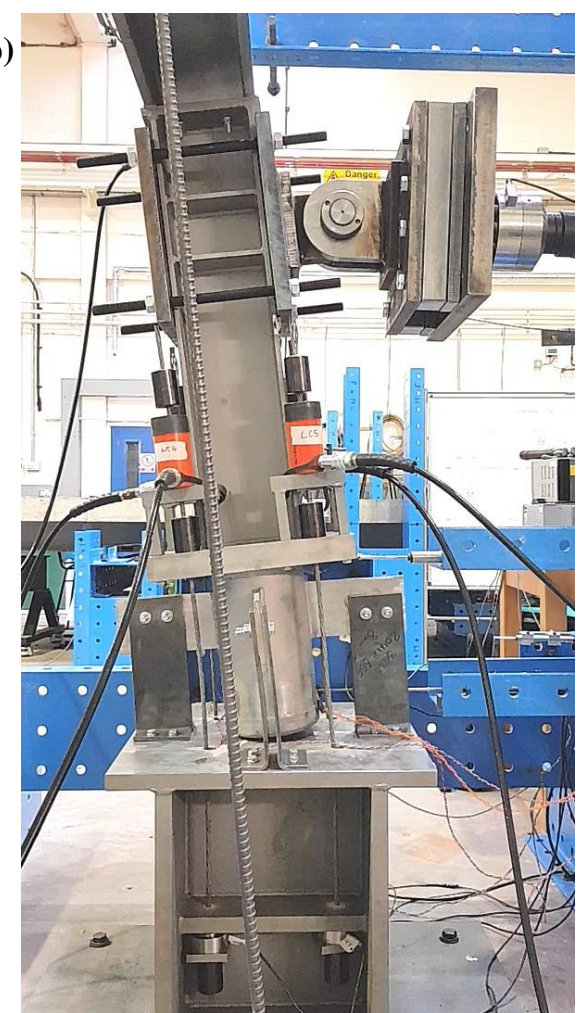

Fig. 19. Cyclic test for column type D. (a) Column rocking on the right edge with 0.095 rads $(9.5 \%$ drift) and (b) 
a)

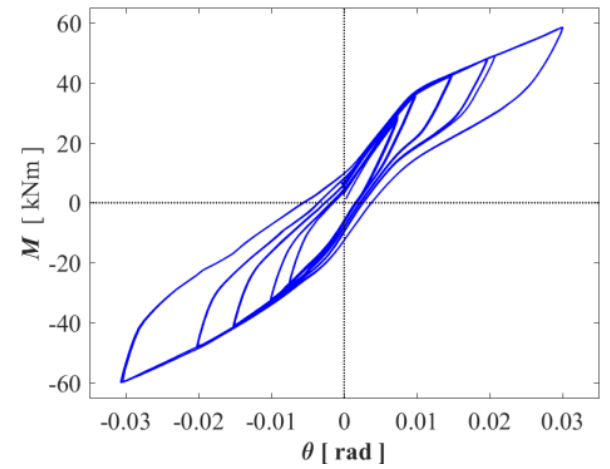

b)

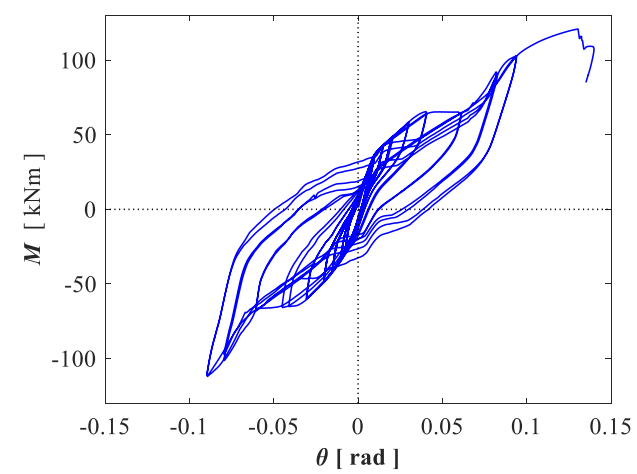

478 479

Fig. 20. Moment-rotation curve of the cyclic test for column type $D$ for (a) cycle types from 1 to 5 with displacements amplitudes up to $33 \mathrm{~mm}$ (0.0314 rads, $3.14 \%$ drift); (b) cycle for the whole test

480 

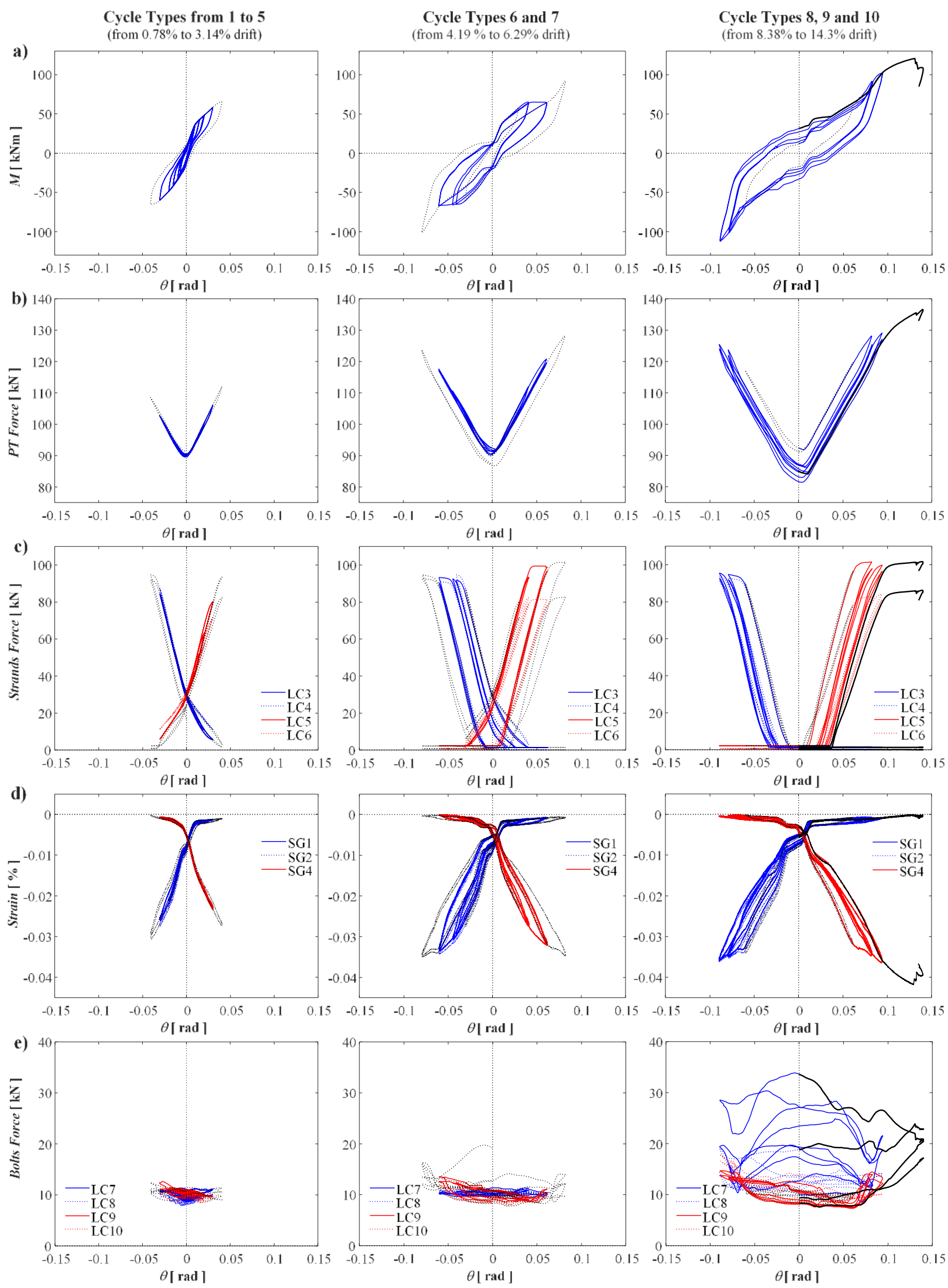

Fig. 21. Cyclic test for column type D. (a) Moment-rotation curve; (b) PT bars' tension force; (c) strands' tension 483 force; (d) strain gauges' records and (e) bolts' tension force 
For cycle types 1 to 5 of Fig. 21, the results were similar as that shown in Fig. 18 and were previously described.

485 For cycle type 6, and 7, Fig. 21(c) shows the strands' yielding which resulted in an increase of deformation with a 486 nearly constant force. It is interesting to observe that the point when the first strands yielded, and the first loss of post487 tensioning force correspond to a rotation of about 0.03 rads, as expected from the design. As a consequence of the 488 yielding and of the residual elongation of the strands, their force corresponding to a zero rotation is equal to zero (i.e., 489 loss of post-tensioning force) at the end of cycle type 7. This affected the moment-rotation curve, shown in Fig. 21(a), 490 where the post-elastic behavior exhibited low strain-hardening and reduction of the initial stiffness of the column base. 491 Fig. 21(d) shows small post-elastic behavior of the column base's hollow section, as described by the strain gauges 492 records. For these amplitudes there is no bearing of the FDs' bolts, as expected, based on the dimensions of the slotted 493 holes and there was a nearly constant bolt tension force as shown in Fig. 21(e).

494 For cycle types 8, 9, and 10, Fig. 21(a) shows a significant increase of the stiffness in the moment-rotation curve.

495 This is related to the bolts bearing, which was expected considering that the slotted holes of the FD were designed for 496 rotations up to 0.06 rads and as a consequence, Fig. 21(e) shows a significant increase of the longitudinal bolts' tension force. Moreover, the increase of rotation amplitudes leaded to further yielding of the strands and of the hollow section 498 of the column base, as shown in Fig. 21(c) and (d). Additionally, Fig. 21(b) shows the behavior of the PT bars that, in 499 this case, experienced small plastic deformations and loss of PT force. However, this small reduction of the axial force 500 in the column do not significantly affect the final results of the experimental test.

501 The black solid lines, shown in the figures for cycle types 8,9 , and 10 , show the final monotonic increase of 502 displacement leading to failure. Failure of one of the base bolts of the longitudinal FD in tension was observed for a 503 rotation of about 0.014 rads (14\% drift) as shown in Fig. 22(a).

504 Observation of the specimen after the final test allowed to identify the damaged components, i.e., the strands and 505 the FDs undergoing plastic deformations. Fig. 22(a) and (b) show respectively the failure in the bolt and the residual deformation in the base plates of the FD, while Fig. 22(c) shows the residual deformations in one strand. For amplitudes within the target design rotation $\left(\theta_{\Gamma}=0.03\right.$ rads $)$, the column base showed damage-free behavior, while

508 for very high rotations, even those significantly beyond the rotations of interest in earthquake engineering $(\theta \sim 0.14)$,

509 the column base showed the ability to isolate damage in few easily replaceable components, demonstrating its high 510 potential to be used in highly earthquake-resilient steel structures. 
a)

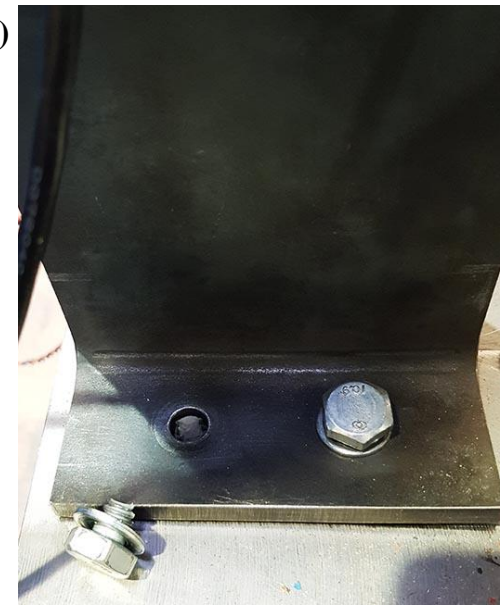

b)

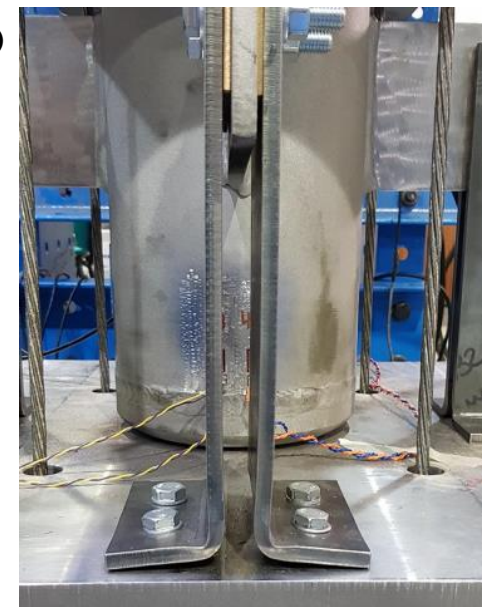

c)

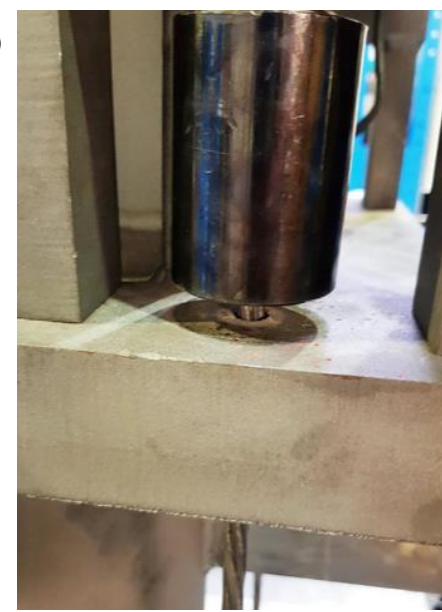

512

513

Fig. 22. Damage observed after the final cyclic test for column type D. (a)
deformations in the FDs' plates and (c) residual deformations in the strands

\section{NUMERICAL ANALYSIS}

A detailed 3D numerical model of the column base was developed in ABAQUS (2013). All the components were modeled using the eight-node linear brick element, which relies on reduced integration and hourglass control, while meshing was carried out using the structured and swift mesh techniques. The multi-point constraint was used to simulate the weldings (i.e., monolithic connection), while the contacts were modeled by the surface-to-surface interaction property. This was implemented by the no penetration contact condition for the behavior in the normal direction with the interface plane and by the penalty method for the tangential response. In the FDs the friction coefficient was defined based on the results of the characterization tests. The initial post-tensioning forces in bolts was modeled such as it remains constant throughout the analysis, differently, for the PT bars the post-tensioning force can varies according to the elongation or shortening during rocking. The nonlinear behavior of the materials was modeled by the von Mises yield criterion coupled with isotropic hardening by using the material properties obtained by the coupon tests. The static analysis procedure was used to solve the nonlinear equilibrium equations while the standard Newton solution technique was used for the application of the loads. Additional modeling details are provided in Freddi et al (2017).

533 Similar results were obtained for the other types, C and D. 
The main difference between the numerical and experimental results is related to the reduced initial stiffness

535 measured in the experimental tests and observed through comparison of the moment-rotation curves shown in Fig.

536 24(a) and (b). This is often the case when comparing experimental and numerical results, and in the present case, this 537 difference is mainly related to the imperfections in the coupling between the column base plate with the steel basement.

Fig. 23. Finite Element Model of the experimental test in ABAQUS (2013)

a)

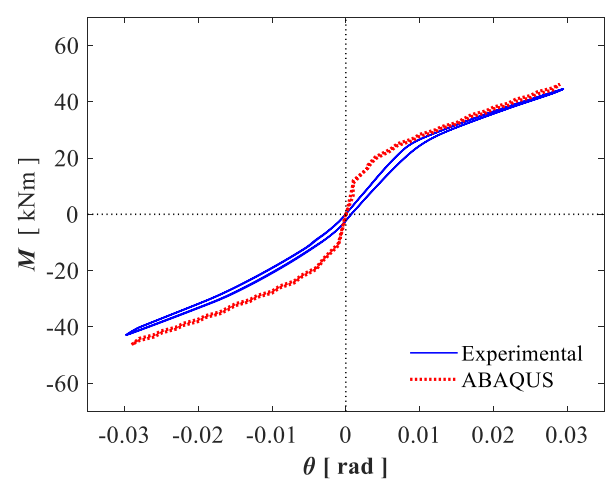

c)

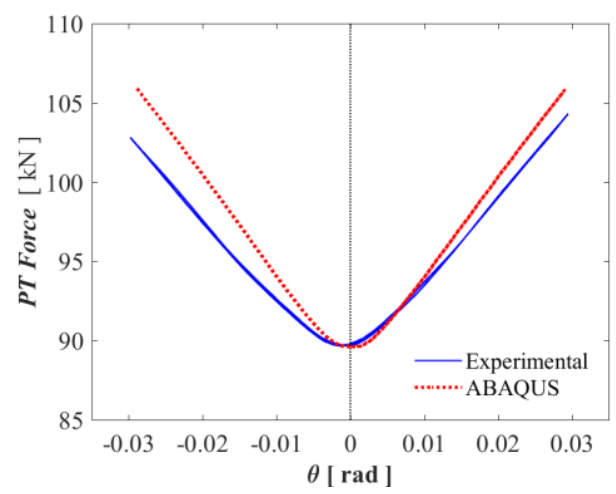

b)

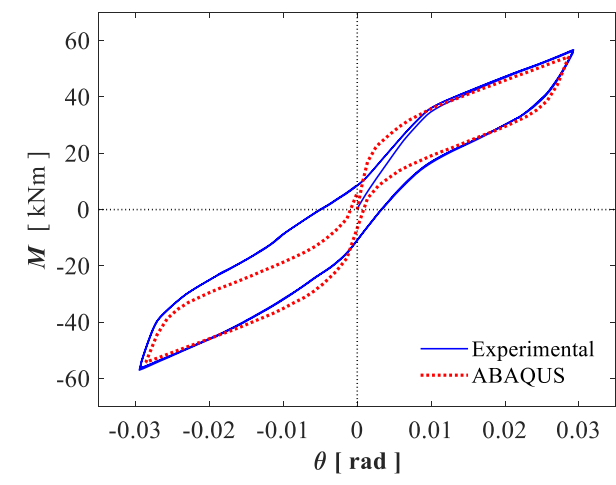

d)

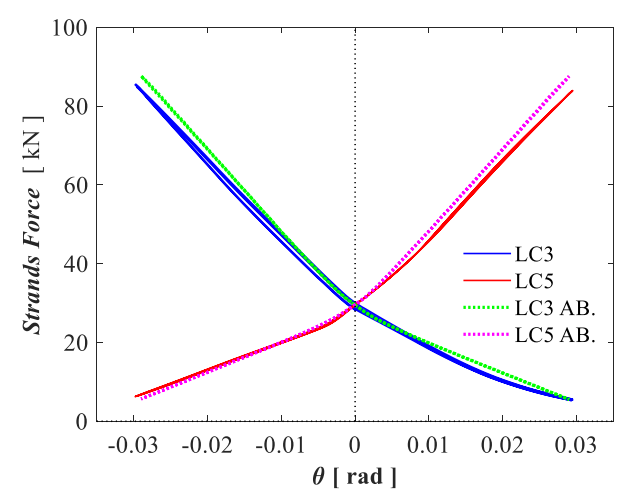

Fig. 24. Comparison between the experimental and numerical results in ABAQUS for the cyclic test up to the target rotation for: (a) Moment-rotation curve of column base type B; (b) Moment-rotation curve of column base type D. 
544 Imperfections have been assessed according to the EN 1090-2 (2008) and included in the numerical ABAQUS models

545 for the column base type D. The considered imperfection consisted of geometrical deviation in the plate with rounded 546 edges and affected the contact conditions.

547 Without the imperfection, the central part of the steel plate with rounded edges is flat and in full contact with the 548 steel basement. If the model account for these imperfections, the contact surface is limited before rocking. The local 549 imperfection has been modeled as a symmetrical geometrical deviation as shown in Fig. 25(a).

a)

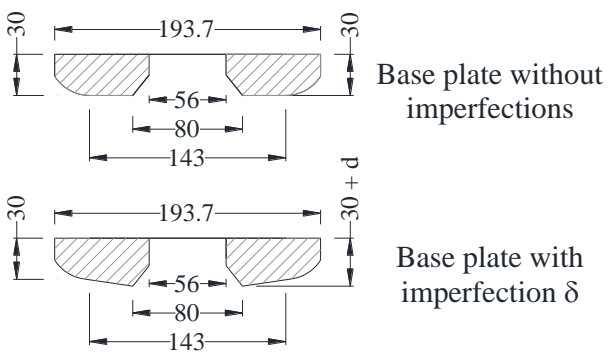

b)

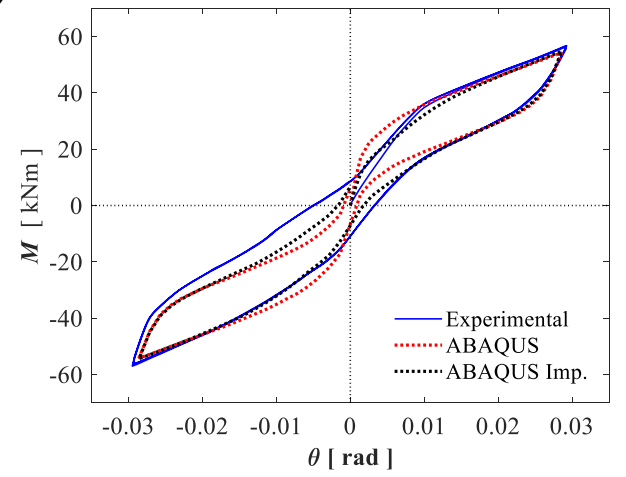

Fig. 25. (a) Imperfections modelling: geometrical deviation in the plate with rounded edges; (b) Comparison between the experimental and numerical moment-rotation curves for the cyclic test up to the target rotation for the of column base type D. ABAQUS models with and without imperfections

Several geometrical deviation amplitudes $\delta$ were investigated, i.e., $0.3 \mathrm{~mm}, 0.7 \mathrm{~mm}, 1.0 \mathrm{~mm}$ and $1.4 \mathrm{~mm}$ and compared with the 'perfect' model $(\delta=0.0 \mathrm{~mm})$. Fig. 25(b) shows, for the column type D, the comparison of the experimental results with the numerical results for the 'perfect' model and the model with a geometrical deviation with amplitude $\delta=0.3 \mathrm{~mm}$. The comparison shows the impact that the imperfection can have on the initial stiffness without though affecting the moment-rotation response for rotations after the decompression.

Fig. 26 shows the comparison of the contact stresses for different rotation values of the column base with and without imperfections. It can be observed that the evolution of contact stresses is significantly different at the beginning of rocking, i.e., the contact surface 'moves quickly' to the steel plate edge in the 'perfect' model while the transition requires a larger rotation in the case with imperfections. This influences the initial stiffness of the system. As a consequence of the imperfections, the distribution of stresses in the initial phase is significantly different, i.e., at the end of post-tensioning of the PT bars and strands, the contact stresses are very localized in the imperfect models at the position where the imperfection amplitude is largest, while in the 'perfect' case, the contact stresses are distributed nearly uniformly over the whole surface of the steel plate. 


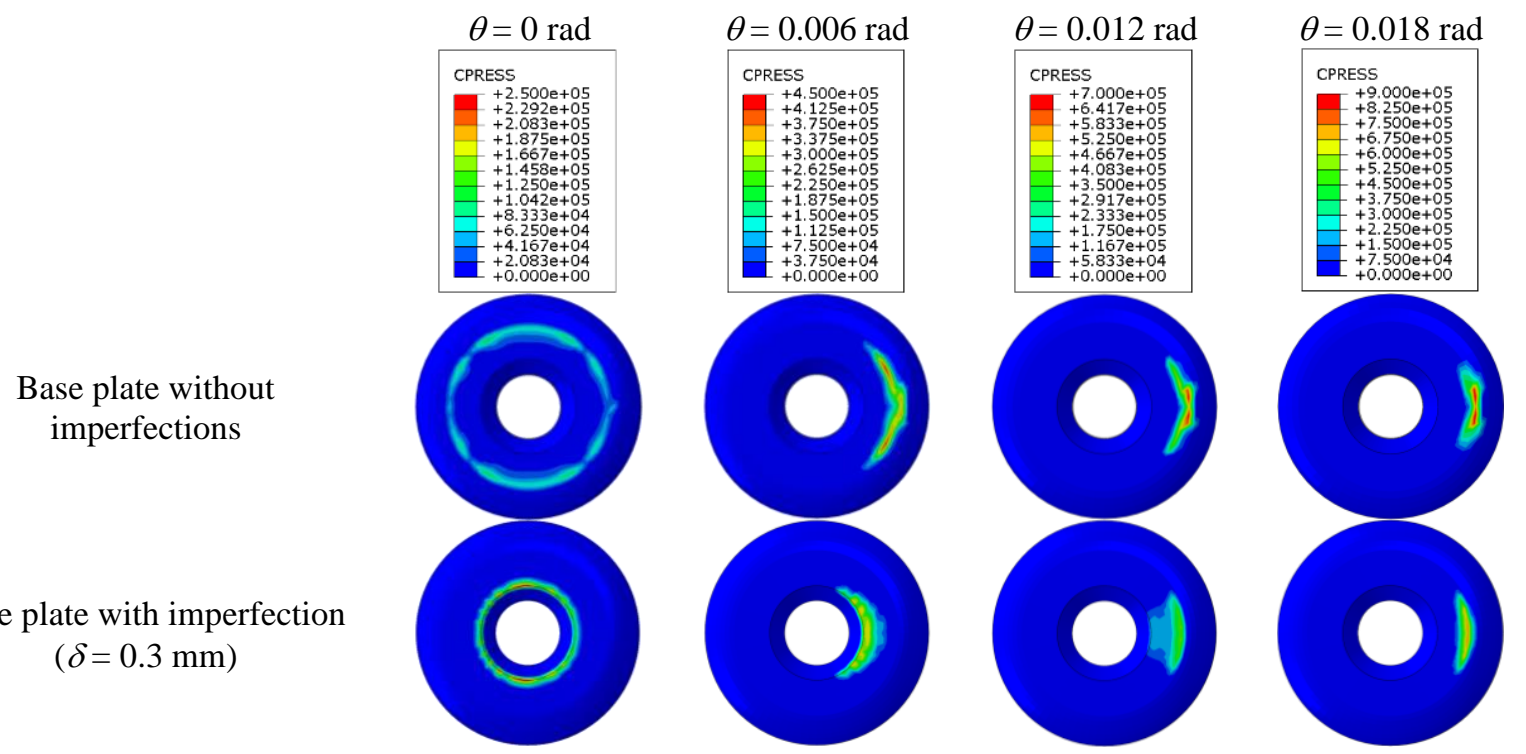

567 Fig. 26. Contact stresses for different rotation values of column base with and without imperfections

568 The results show that the initial stiffness of the rocking system is significantly affected by this type of initial 569 imperfection. Careful manufacturing process would allow a reduction of initial imperfection improving the confidence 570 on the column base behavior. However, the results show that, even without considering the imperfections, the 571 analytical formulation and the numerical model allow to capture the behavior of the column base after the 572 decompression moment.

\section{CONCLUSIONS}

574 An earthquake-resilient rocking steel column base previously proposed and numerically investigated by the authors

575 is experimentally tested. The proposed column base can be used to reduce residual deformations and damage in 576 'innovative' MRFs where the variations in the axial force associated with seismic overturning moment is limited. The 577 column base uses post-tensioned (PT) high strength steel bars to control rocking behavior and friction devices (FDs) 578 to dissipate seismic energy. A column base extracted from a prototype steel building was designed using a step-by579 step design procedure, previously proposed by the authors, that aims to achieve damage-free and self-centering 580 behavior for a predefined target rotation. Component tests for the characterization of the FDs were conducted to assess 581 the relationship between the torque applied to high-strength bolts and the resistance (force corresponding to initiation 582 of sliding) of the FDs. The experimental tests were conducted on a 3/5 scaled column base under monotonic and cyclic 583 quasi-static lateral loading protocols while simulating an about constant axial force. The experimental results showed 584 good agreement with the expected behavior from analytical equations, which validated the design procedure. 
Moreover, they demonstrated the damage-free behavior up to the target design rotation and the ability to limit the

586 damage only to few easily replaceable components under large rotations. This demonstrates the high potential of the

587 innovative column base to be used in earthquake-resilient steel structures. The experimental results were also used to

588 calibrate refined 3D numerical models in ABAQUS that allowed to investigate the influence of the imperfections.

589 Amongst others, future research should focus on performing experimental dynamic tests to fully assess the seismic

590 performance of the proposed column base allowing the evaluation of the effect of the energy radiated during impact.

591 Moreover, additional research is required to reduce the uncertainty of the FDs response as consequence of the 592 variability of the bolt preload and the friction coefficient with time.

\section{DATA AVAILABILITY}

594 All data, models, or code generated or used during the study are available from the corresponding author by request.

\section{ACKNOWLEDGEMENTS}

596 This research is supported by Marie Sklodowska-Curie Action Fellowships within the H2020 European Programme.

597 Any opinions, findings, and conclusions or recommendations expressed in this paper are those of the authors and do 598 not necessarily reflect the views of the European Commission. The Authors also gratefully acknowledge the support 599 of Prof. J. Toby Mottram and the work of the technicians of the Structural Testing Laboratory of the University of 600 Warwick: Taylor Arnett and Neil Gillespie.

\section{REFERENCES}

602 ABAQUS/Standard and ABAQUS/Explicit - Version 6.13.1. ABAQUS Theory Manual, Dassault Systems, 2013.

603 Akcelyan, S., Lignos, D.G., Hikino, T., Nakashima, M. (2016). "Evaluation of Simplified and State-of-the-Art 604 Analysis Procedures for Steel Frame Buildings Equipped with Supplemental Damping Devices Based on E605 Defense Full-Scale Shake Table Tests." J. Struct. Eng.; 142(6), 04016024.

606 ANSI/AISC 341-05. (2005) "Seismic Provisions for Structural Steel Buildings." American Institute of Steel 607 Construction, Chicago, Illinois.

608 Blomgren H-E., Pei, S., Jin, Z., Powers, J., Dolan, J.D., van de Lindt, J.W., Barbosa, A.R., Huang, D. (2019). "Full609 Scale Shake Table Testing of Cross-Laminated Timber Rocking Shear Walls with Replaceable Components.” J. $610 \quad$ Struct. Eng.; 145(10), 04019115.

611 Borzouie, J., MacRae, G.A., Chase, J.G., Rodgers, G.W., Clifton, G.C. (2015). "Experimental studies on cyclic 
612 performance of column base strong axis - aligned asymmetric friction connections." J. Struct. Eng.; 142(1), $613 \quad 04015078,1-10$.

614 BSI Standards Publication. (2012). "High tensile steel wire and strand for the prestressing of concrete - Specification".

615 BS 5896:2012, The British Standards Institution, London, UK.

616 Chi, H., Liu, J. (2012). "Seismic behavior of post-tensioned column base for steel self-centering moment resisting 617 frame.” J. Constr. Steel Res., 78, 117-130.

618 Chou, C-C., Chen, J.H. (2011). "Analytical model validation and influence of column bases for seismic responses of 619 steel post-tensioned self-centering MRF systems.” Eng. Struct., 33(9), 2628-2643.

620 Coelho, A., Bijlaard, F., Gresnigt, N., da Silva, L.S. (2004). "Experimental assessment of the behavior of bolted T621 stub connections made up of welded plates.” J. Constr. Steel Res.; 60(2), 269-311.

622 CSI SAP2000. (2011). "Linear and Nonlinear Static and Dynamic Analysis and Design of Three-Dimensional 623 Structures: Basic Analysis Reference Manual”. Computers and Structures, Inc. Berkeley, California.

624 Dimopoulos, A.I., Tzimas, A.S., Karavasilis, T.L., Vamvatsikos. D. (2016). "Probabilistic economic seismic loss 625 estimation in steel buildings using post-tensioned moment-resisting frames and viscous dampers." Earthquake 626 Eng. Struct. Dyn.; 45(11), 1725-1741.

627 Dimopoulos, C., Freddi, F., Karavasilis, T. (2019). "Progressive collapse resistance of steel self-centering MRFs including the effects of the https://doi.org/10.1016/j.engstruct.2019.109923

EN 1090-2. (2008) "Execution of steel structures and aluminum structures - Part 2: Technical requirements for steel structures.” European Committee for Standardization, Brussels, Belgium.

634 EN 1993-1-1. (2005). "Eurocode 3: Design of steel structures - Part 1-1: General rules and rules for buildings." 635 European Committee for Standardization, Brussels, Belgium.

636 EN 1993-1-8. (2005). "Eurocode 3: Design of steel structures - Part 1-8: Design of Joints.” European Committee for 637 Standardization, Brussels, Belgium.

638 EN 1998-1-1. (2005). "Eurocode 8: Design of structures for earthquake resistance - Part 1: General rules, seismic 639 action and rules for buildings.” European Committee for Standardization, Brussels, Belgium. 
EN ISO 6892-1. (2009) "Metallic materials - Tensile testing - Part 1: Method of test at room temperature."

641 European Committee for Standardization, Brussels, Belgium.

642 Federal Emergency Management Agency (FEMA). (2000). "Recommended seismic design criteria for new steel

643 moment-frame buildings." FEMA 350, SAC Joint Venture, Washington, DC.

644 Freddi, F., Tubaldi, E., Ragni, L., Dall'Asta, A. (2013). "Probabilistic performance assessment of low-ductility

645 reinforced concrete frame retrofitted with dissipative braces.” Earthquake Eng. Struct. Dyn.; 42(7), 993-1011.

646 Freddi, F., Dimopoulos, C.A., Karavasilis, T.L. (2017). "Rocking damage-free steel column base with friction devices:

647 design procedure and numerical evaluation.” Earthquake Eng. Struct. Dyn.; 46(14): 2281-2300. DOI:

$648 \quad 10.1002 /$ eqe. 2904.

649 Garlock, M., Sause, R., Ricles, J.M. (2007). "Behavior and design of posttensioned steel frame systems.” J. Struct.

650 Eng.; 133(3), 389-399.

651 Gioiella, L., Tubaldi, E., Gara, F., Dezi, L., Dall'Asta A. (2018). "Modal properties and seismic behaviour of buildings 652 equipped with external dissipative pinned rocking braced frames.” Eng. Struct.; 172, 807-819.

653 Grauvilardell, J.E., Lee, D., Hajjar, J.F., Dexter, R.J. (2006). "Synthesis of design, testing and analysis research on 654 steel column base plate connections in high-seismic zones.” Report ST-04-02, Dept. of Civil Engineering, Univ. 655 of Minnesota, USA.

656 Grigorian, C.E., Yang, T.S., Popov, E.P. (1993). "Slotted bolted connection energy dissipators.” Earthq. Spectra: 9(3): $657 \quad 491-504$.

658 Haremza, C., Santiago, A., da Silva, L.S. (2013). "Experimental behavior of heated composite steel-concrete joints 659 subject to variable bending moments and axial forces.” Eng. Struct.; 51, 150-161.

660 Ikenaga, M., Nagae, T., Nakashima, M., Suita, K. (2006). "Development of column bases having self-centering and 661 damping capability." $5^{\text {th }}$ Int. Conf. on Behaviour of Steel Structures in Seismic Areas, Yokohama, Japan.

662 Kamperidis, V.C., Karavasilis, T.L., Vasdravellis, G. (2018). "Self-centering steel column base with metallic energy 663 dissipation devices.” J. of Constr. Steel Res.; 149, 14-30.

664 Kanvinde, A.M., Grilli, D.A., Zareian, F. (2012). "Rotational stiffness of exposed column base connections: 665 experiments and analytical models.” J. Struct. Eng.; 138(5), 549-560.

666 Kelly, J.M., Tsztoo, D.F. (1977). "Earthquake simulation testing of a stepping frame with energy-absorbing devices. 667 NZ Soc. Earthquake Eng. Bull.; 10(4): 196-207.

668 Kim, H.J., Christopoulos, C. (2008). "Seismic design procedure and seismic response of post-tensioned self-centering 
steel frames." Earthquake Eng. Struct. Dyn., 38(3), 355-376.

670 Latour, M., Rizzano, G. (2013). "Full strength design of column base connections accounting for random material 671 variability.” Eng. Struct.; 48, 458-471.

672 Latour, M., Rizzano, G. (2013). “A theoretical model for predicting the rotational capacity of steel base joints.” Eng. 673 Struct.; 91, 89-99.

674 Latour, M., Piluso, V., Rizzano, G. (2015). "Free from damage beam-to-column joints: Testing and design of DST 675 connections with friction pads.” Eng. Struct.; 85, 219-233.

676 Latour, M., Rizzano, G., Santiago, A., da Silva, L.S. (2019). "Experimental response of a low-yielding, re-centering, 677 rocking base plate joint with friction dampers.” Soil Dyn. Earthq. Eng.; 116: 580-592.

678 Mackinven, H., MacRae, G.A., Pampanin, S., Clifton, G.C., Butterworth, J. (2007). "Generation four steel moment 679 frame joints." $8^{\text {th }}$ Pacific Conf. on Earthq. Eng., Singapore.

680 MacRae, G.A., Urmson, C.R., Walpole, W.R., Moss, P., Hyde, K., Clifton, C. (2009). "Axial shortening of steel 681 columns in buildings subjected to earthquakes.” Bull. New Zeal. Soc. Earthq. Eng., 42(4): 275-287.

682 McKenna, F., Fenves, G.L., Scott, M.H. (2006). “OpenSees: Open system for earthquake engineering simulation.”

683 PEER Center, Berkeley, CA.Wolski, M., Ricles, J., Sause, R. (2009). “Experimental Study of a Self-Centering

684 Beam-Column Connection with Bottom Flange Friction Device.” J. Struct. Eng.; 135(5), 479-488.

685 Rodas, P.T., Zareian, F., Kanvinde, A. (2016). "Hysteretic model for exposed column-base connections.” J. Struct. 686 Eng.; 142(12), 04016137, 1-14.

687 Symans, M.D., Charney, F.A., Whittaker, A.S., Constantinou, M.C., Kircher, C.A., Johnson, M.W., McNamara, R.J. 688 (2008). "Energy dissipation systems for seismic applications: Current practice and recent developments." J. Struct. 689 Eng.; 134(1), 3-21.

690 Takamatsu, T., Tamai, H. (2005). "Non-slip-type restoring force characteristics of an exposed-type column base.” J. $691 \quad$ Constr. Steel Res. 61(7): 942-961.

692 Tzimas, A.S., Kamaris, G.S., Karavasilis, T.L., Galasso, C. (2016). "Collapse risk and residual drift performance of 693 steel buildings using post-tensioned MRFs and viscous dampers in near-fault regions." Bulletin Earthq. Eng.; 694 14(6), 1643-1662.

695 Vasdravellis, G., Karavasilis, T.L., Uy, B. (2013). "Large-scale experimental validation of steel posttensioned 696 connections with web hourglass pins.” J. Struct. Eng.; 139(6), 1033-1042.

697 Wang, X.T., Xie, C.D., Lin, L.H., Li, J. (2019). "Seismic behavior of self-centering concrete-filled square steel tubular 
699 Yamanishi, T., Kasai, K., Takamatsu, T., Tamai, H. (2012). "Innovative column-base details capable of tuning rigidity 700 and strength for low to medium-rise steel structures." $15^{\text {th }}$ World Conf. on Earthq. Eng., Lisbon, Portugal.

701 Zareian, F., Kanvinde, A. (2013). "Effect of column-base flexibility on the seismic response and safety of steel 702 moment-resisting frames.” Earthq. Spectra; 29(4), 1537-1559. 